\title{
Revisando las primeras producciones vidriadas islámicas cordobesas a la luz de la arqueometría
}

\author{
Revisiting the earliest Islamic glazed ceramics of Córdoba from an \\ archaeometric approach \\ Elena Salinas* \\ Trinitat Pradell*
}

\begin{abstract}
RESUMEN
En este artículo se propone una revisión de las primeras cerámicas vidriadas andalusíes. A partir de análisis arqueométricos se caracterizan los primeros vidriados, se tratan los problemas de conservación y alteración de estas producciones y se identifican las diferentes tradiciones tecnológicas que convivieron a finales del emirato en Córdoba. Además se buscan las conexiones tecnológicas con otros territorios islámicos y bizantinos.
\end{abstract}

Palabras claves: Vidriados, Cerámicas decoradas, Verde y manganeso, Tecnología del vidriado, Vidriado transparente de plomo, Vidriado opaco de estaño, al-Andalus, Emiral.

\section{INTRODUCCIÓN}

Hace unos años publicábamos un conjunto excepcional de cerámica vidriada emiral, localizado en el arrabal del Sabular de Córdoba (MORENO et alii, 2006; SALINAS, 2013). A raíz de su estudio con técnicas arqueométricas presentamos una actualización de los resultados. Además, se comparará con otro conjunto cordobés contemporáneo (SALINAS y PRADELL, 2018) y con nuevos datos procedentes de los dos centros productores de cerámica vidriada andalusíes más antiguos: los procedentes del área alfarera emiral de Córdoba (SALINAS y PRADELL, en prensa) y el taller de cerámica vidriada de Pechina (SALINAS et alii, 2019a) (Fig. 1).

\begin{abstract}
In this paper a review of the earliest glazed ceramics from al-Andalus is proposed. From archaeometrical analyses, the first glazes are characterised, their preservations and alteration problems are explained, and the different technological traditions that coexisted during the Late Emirate period in Córdoba are identified. Moreover, technological connections are sought with other contemporary Islamic and Byzantine territories.
\end{abstract}

Keywords: Glazes, Polychrome decoration, Glaze technology, Lead transparent glaze, Tin-opaque glazes, al-Andalus, Emirate period.

Proponemos una revisión de las diferentes tradiciones tecnológicas utilizadas en el conjunto estudiado, que han resultado clave para entender la evolución de la tecnología del vidriado en al-Andalus en una etapa temprana.

En aquel primer artículo proponíamos una primera caracterización de los primeros vidriados cordobeses basada en criterios morfológicos y ornamentales, pero no tecnológicos. También buscábamos posibles influencias e identificación de paralelos con otros lugares de la Dar al-Islam. Aunque aún no habían sido encontradas las evidencias de una producción temprana local de vidriado, se defendió la existencia de un centro productor de cerámica

\footnotetext{
* Departamento de Física y Centro de Investigación en Ciencia e Ingeniería Multiescala de Barcelona, Universitat Politècnica de Catalunya
} 

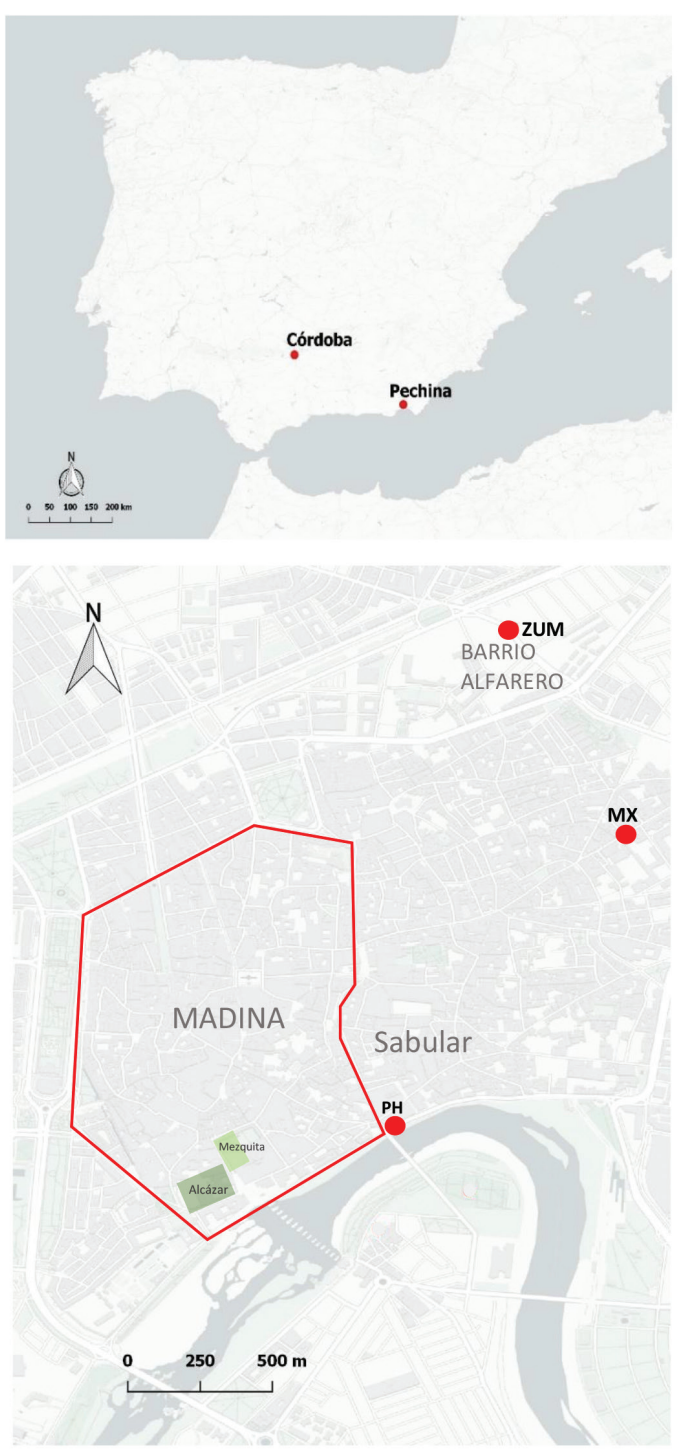

Fig. 1. A. Localización de Córdoba y Pechina. B. Plano de Córdoba tardoemiral donde se ha situado la excavación arqueológica de la Posada de la Herradura (PH) y otras intervenciones arqueológicas donde se han hallado cerámicas vidriadas emirales: Zumbacón (ZUM) y María Auxiliadora (MX).

vidriada en Córdoba, a partir de hallazgos bien datados en el registro arqueológico cordobés y que adelantaban el inicio de las primeras producciones verde y manganeso a un momento tardoemiral y no califal, como tradicionalmente se había pensado.

En los últimos años, el estudio de la historia y arqueología medieval se ha visto favorecido por la aplicación de metodologías interdisciplinares, basadas en disciplinas científicas, que han permitido un avance en la investigación. El objetivo de este artículo es realizar una caracterización tecnológica de las piezas, diferenciar las tecnologías del vidriado del conjunto y revisar las tesis defendidas en el primer artículo.

\section{EL CONJUNTO CERÁMICO VIDRIADO DE LA POSADA DE LA HERRADURA: EL POZO NEGRO DEL ARRABAL DEL SABULAR}

Este repertorio es excepcional puesto que es el único contexto cerrado datado en época emiral que presenta piezas cerámicas que corresponden a tres tecnologías de vidriado diferentes: monocromo/bícromo transparente de plomo (entiéndase por bícromo que las caras exterior e interior presentan cada una un color diferente, pero nunca combinados en la misma superficie), polícromo transparente de plomo y vidriados opacificados con estaño. La primera tecnología de los vidriados monocromos y bícromos se conocía mejor, desde el punto de vista tipológico y decorativo, gracias a los hallazgos y publicaciones de Pechina (p. ej. CASTILLO y MARTÍNEZ, 1993), y ha sido recientemente abordada con un enfoque tecnológico (SALINAS et alii, 2019a). La producción polícroma transparente es muy interesante porque representa una mayor complejidad técnica, cuando los vidriados comenzaron a decorarse con trazos pintados; no se tenía constancia de ellos en al-Andalus durante la etapa emiral. Esta producción tuvo una vida muy corta porque pronto fue sustituida por la producción estannífera, al menos en Córdoba. Es cierto que en un momento avanzado del Califato, se documenta una producción de "verde y manganeso" sobre fondo vidriado transparente de plomo (es decir, sin estaño) de color melado, que se consigue añadiendo óxido de hierro al vidriado y que, probablemente, corresponda a una producción más económica. Por el contrario, los vidriados transparentes de plomo polícromos emirales no tienen colorantes añadidos y el color de fondo lo proporciona la coloración de la pasta 
cerámica: si esta es naranja, debido a que se ha cocido en una atmósfera oxidante, el vidriado es amarillo y, conjuntamente con el color rojizo de la cerámica, le da un color miel "melado"; y si la pasta es gris, porque fue cocida en una atmosfera reductora, el color es verdoso. Por último, se documentó la primera producción de "verde y manganeso" emiral, en la que se está utilizando el estaño para conseguir un fondo blanco sobre el que dibujar trazos negros y verdes. Para su estudio, se seleccionaron quince piezas cerámicas representativas de estas tres tradiciones tecnológicas: vidriados transparentes de plomo monocromos/ bícromos, vidriados transparentes de plomo polícromos y vidriados opacos de estaño. Una característica interesante de estas piezas es su diversidad morfológica y ornamental, lejos de una producción estandarizada. Las cerámicas presentan diferentes formas, colores, diseños y técnicas decorativas. Siguiendo la clasificación de ROSSELLÓ (1978; 1991), la mayoría son de vajilla de mesa (cuencos, vasos, ataifores y jarritos). Completan el conjunto una orza y un candil. Esta heterogeneidad se observa también en la variedad de tipos de ataifores y jarritos. La gama de colores empleada incluye verde, verdoso, melado, marrón/negro, crema y blanco. Las técnicas decorativas también son diversas: pintura, a molde, incisa y con hilos aplicados. Las piezas están ejecutadas con una gran calidad técnica que no perduró en el periodo califal.
En el artículo publicado en el 2013 optamos por una clasificación tipológica atendiendo a criterios morfológicos y funcionales. Ahora hemos optado por una clasificación tecnológica, y como tal la hemos organizado en la Tabla 1 y en las figuras 2, 3, 4 y 5.

Las piezas vidriadas han sido divididas en tres categorías principales según la técnica del vidriado: transparente monocromo/bícromo, transparente polícromo y opacos polícromos (Tabla 1).

Se han analizado dos muestras vidriadas transparentes monocromas: un candil ( $\mathrm{PH} 8)$ con decoración incisa (Fig. 2A) y un ataifor sin pie con decoración a molde (PH20) (Fig. 2B).

El grupo de los transparentes bícromos está compuesto por cuatro piezas: un jarrito (PH9) (Fig. 3A), dos vasos (PH10.1 y PH10.3) (Figs. 3B y D) y un ataifor de borde alado y sin pie (PH11.1) (Fig. 3C). Algunas piezas presentan decoración: dos de ellas tienen hilos aplicados sobre la superficie y dispuestos de manera vertical o romboidal (PH9 y PH10.3), mientras que una de las piezas está fabricada a molde (PH10.1). Todas las piezas tienen la superficie exterior vidriada en melado y la interior vidriada en verde.

Los vidriados transparentes polícromos incluyen cinco piezas: tres ataifores sin pie

Tabla 1. Clasificación de las cerámicas vidriadas. $v$ - vidriado verde, $m$ - vidriado melado, $b$-vidriado blanco, $d$-decorado, $t$-transparente, $i$-interior, e-exterior.

\begin{tabular}{|c|c|c|c|c|}
\hline TIPO & & No MUESTRAS & VIDRIADO & CERÁMICAS \\
\hline \multirow{5}{*}{$\begin{array}{c}\text { Vidriados } \\
\text { Transparentes }\end{array}$} & \multirow{2}{*}{$\begin{array}{c}\text { Transparente } \\
\text { Monocromo } \\
\text { (TM) }\end{array}$} & \multirow{2}{*}{2} & v & $\mathrm{PH} 8$ \\
\hline & & & m & $\mathrm{PH} 2 \mathrm{O}$ \\
\hline & $\begin{array}{c}\text { Transparente } \\
\text { Bícromo } \\
\text { (TB) }\end{array}$ & 4 & $\begin{array}{l}m(\mathrm{e}) / v \\
\text { (i) }\end{array}$ & $\begin{array}{c}\text { PH9, PH10.1, PH10.3, } \\
\text { PH11.1 }\end{array}$ \\
\hline & \multirow{2}{*}{$\begin{array}{c}\text { Transparente } \\
\text { Polícromo } \\
\text { (TP) }\end{array}$} & \multirow[b]{2}{*}{5} & $\mathrm{t}(\mathrm{o}) / \mathrm{d}(\mathrm{i})$ & $\mathrm{PH} 11.3, \mathrm{PH} 12, \mathrm{PH} 16$ \\
\hline & & & $\mathrm{t}(\mathrm{i}) / \mathrm{d}(\mathrm{e})$ & PH18, PH15.2 \\
\hline \multirow{2}{*}{$\begin{array}{l}\text { Vidriados } \\
\text { Opacos }\end{array}$} & \multirow{2}{*}{$\begin{array}{l}\text { Opaco de estaño } \\
\text { (OE) }\end{array}$} & \multirow{2}{*}{4} & b (e) /d (i) & $\mathrm{PH} 13.5, \mathrm{PH} 14, \mathrm{PH} 50$ \\
\hline & & & b (i) /d (e) & PH19 \\
\hline
\end{tabular}



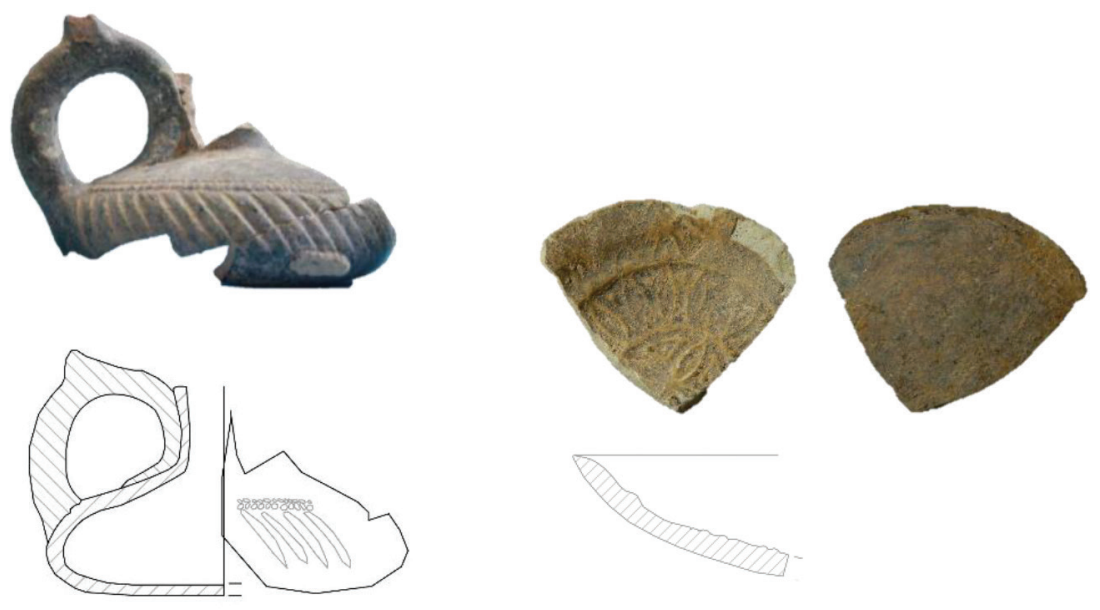

A
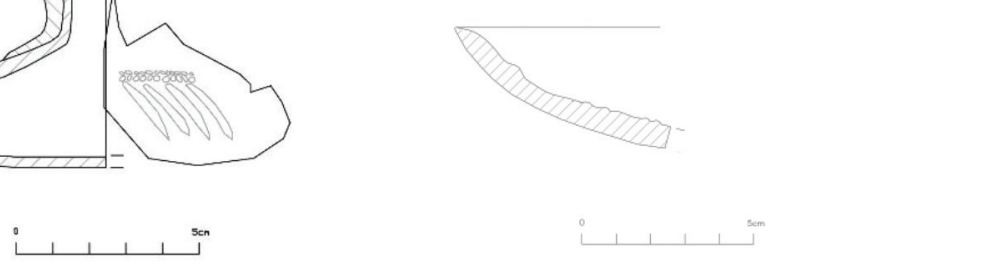

B

Fig. 2. Cerámicas vidriadas transparentes de plomo monocromas de la Posada de la Herradura (PH): (A) PH8 y (B) PH2O.
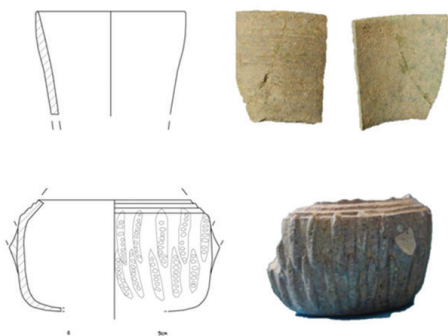

A
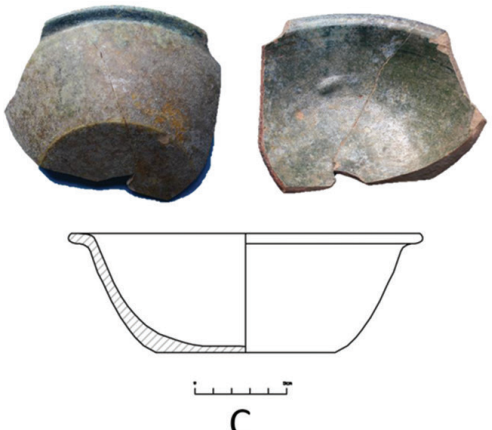

C

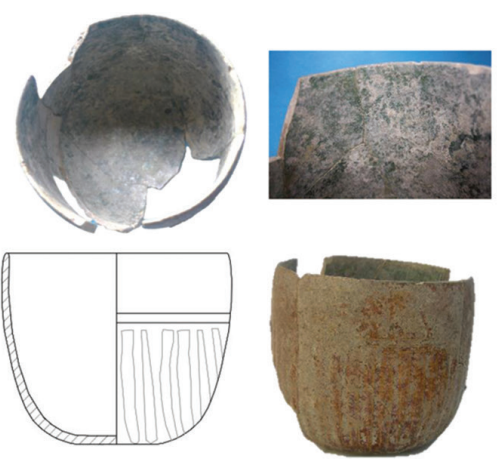

B
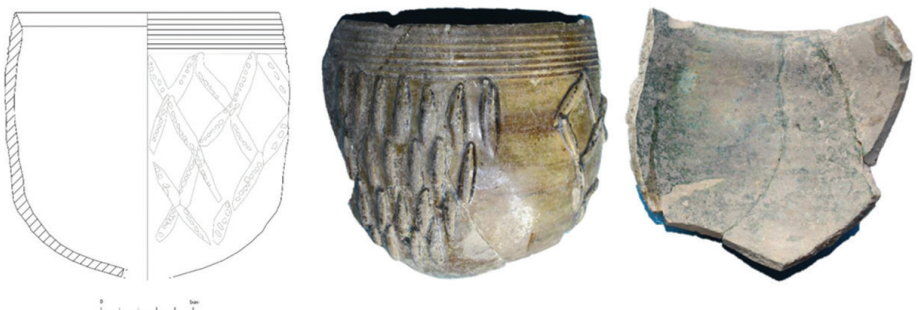

D

Fig. 3. Cerámicas vidriadas transparentes de plomo bícromas de la Posada de la Herradura (PH): (A) PH9, (B) PH10.1, (C) PH11.1 y (D) PH10.3.

(PH11.3, PH12, PH16) (Figs. 4A, B, C) con perfiles de paredes rectas o exvasadas y trazos de colores pintados en la cara interior, una taza (PH15.2) (Fig. 4D) y una orza
(PH18) (Fig. 4E) que presentan su decoración en la cara exterior, que se corresponde con la parte más visible en las formas cerradas. 


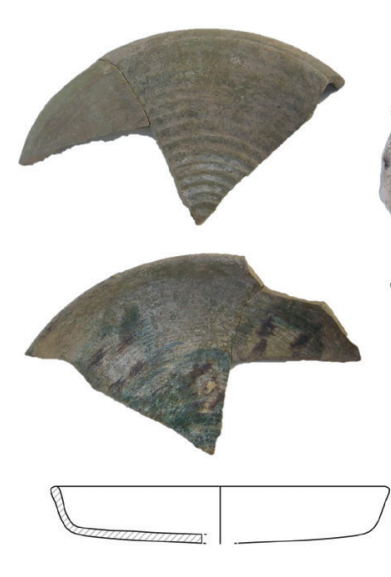

A
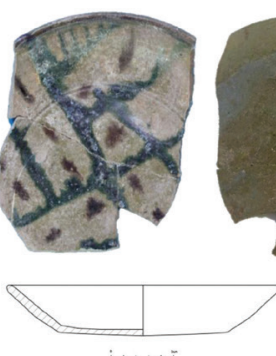

B

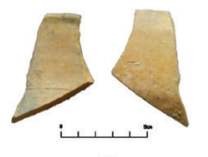

C
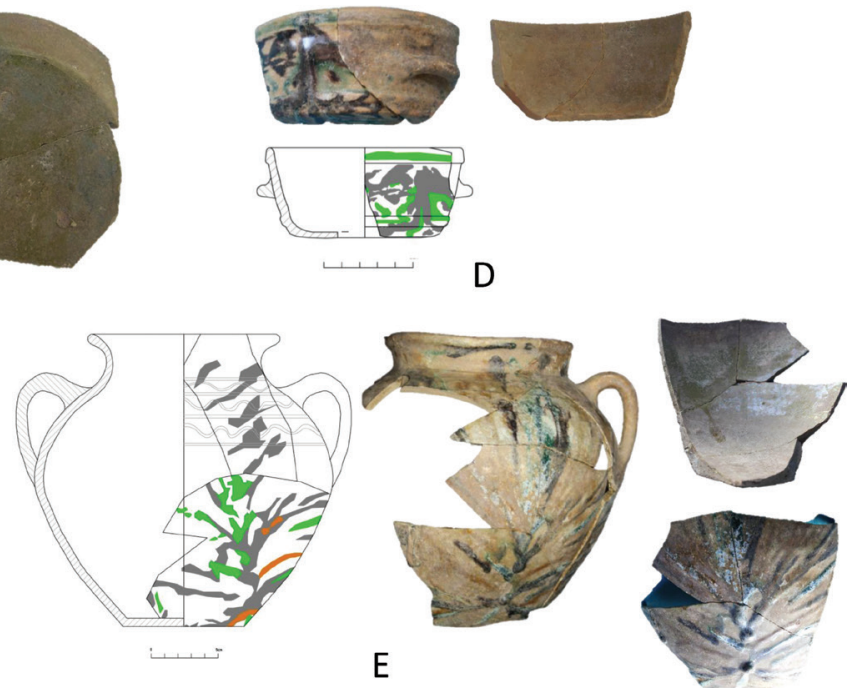

Fig. 4. Cerámicas vidriadas transparentes de plomo polícromas de la Posada de la Herradura (PH): (A) PHI1.3, (B) PH12, (C) PH16, (D) PH15 y (D) PH18.

Un último grupo está formado por los vidriados polícromos opacificados con estaño: cuatro son ataifores de mayor tamaño, perfil hemisférico y sin pie (PH13.5, PH14,
PH50) (Figs. 5A, B, D) y uno corresponde a una forma cerrada sin identificar, que podría identificarse con una especie de orza (PH19) (Fig. 5D).

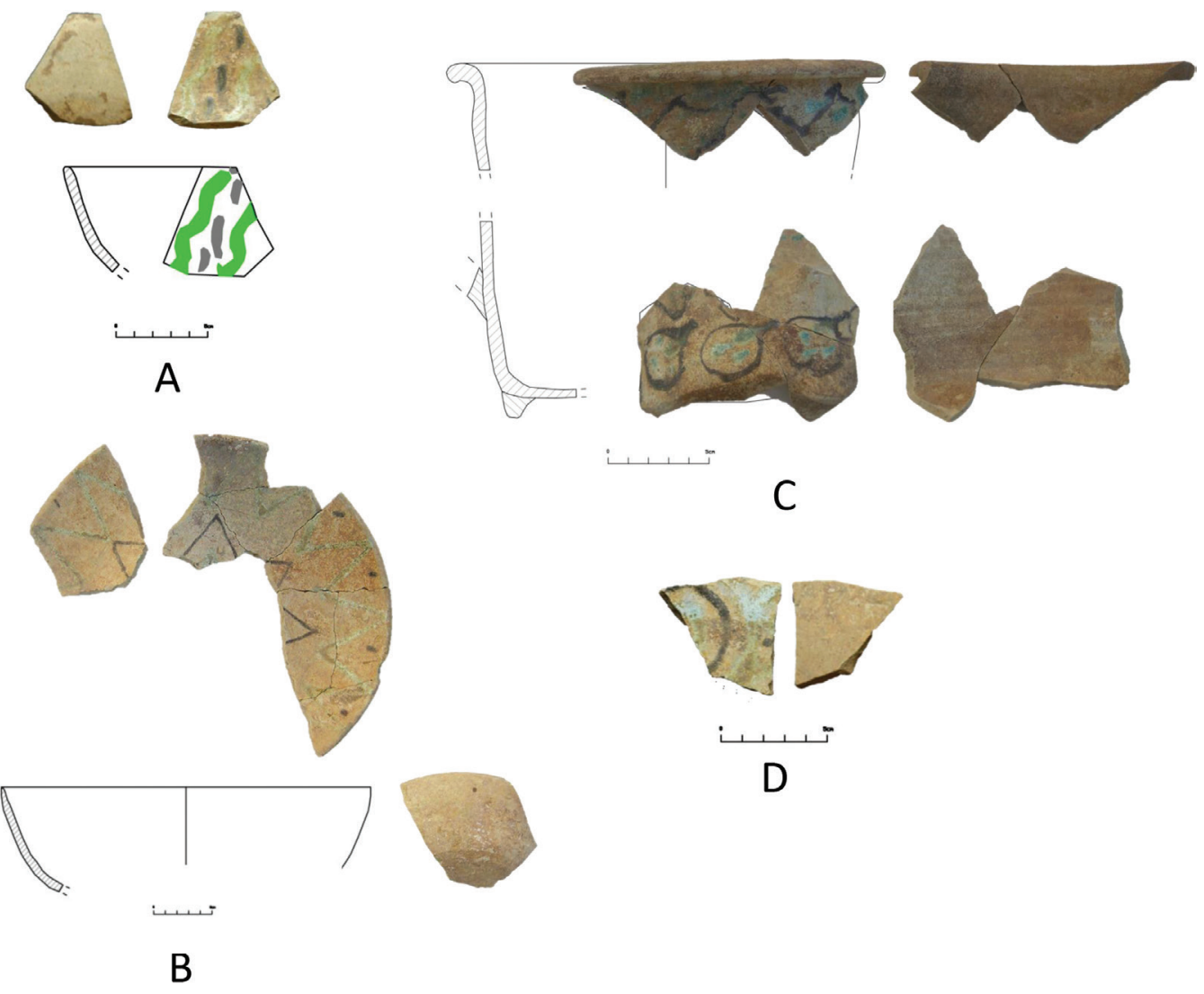

Fig. 5. Cerámicas vidriadas opacas de estaño y polícromas de la Posada de la Herradura (PH): (A) PH13.5, (B) PH14, (C) PH19y (D) PH50. 


\section{MÉTODOS DE ANÁLISIS}

Se han realizado secciones transversales de las muestras, incluyendo vidriados y pastas, tras lo cual se insertaron en moldes y se cubrieron con resina epoxi. El siguiente paso fue pulir los bloques con hojas de diferente granulometría y polvo de diamante para, posteriormente, examinarlas por microscopía óptica (OM). Una vez examinadas se cubrieron de una capa de carbono y se prepararon para su análisis por microscopía electrónica de barrido con detector de energía dispersiva de rayos-X (SEM-EDX), con un equipo SEM GEMINI (Shottky FE) y un detector EDX (INCAPentaFETx3, 30mm², ATW2 window). Las fotografías y los análisis se llevaron a cabo en los laboratorios del Centro de Investigación en Ciencia e Ingeniería Multiescala de la Universitat Politècnica de Catalunya (Barcelona). Se obtuvieron imágenes electrónicas de retrodispersión (BSE) de las microestructuras de las pastas y de los vidriados. Los análisis químicos de las pastas cerámicas fueron determinados por el análisis de dos áreas de $3 \mathrm{~mm}$ x 2 mm, mientras que las áreas analizadas de los vidriados fueron más pequeñas, para evitar zonas exteriores erosionadas o cerca de las interfaces que pudieran alterar los resultados. A causa de la porosidad de las pastas y del estado de conservación de los vidriados, los análisis fueron normalizados a 100 y posteriormente promediados. En general, los totales de las pastas suman aproximadamente un 60\% y los de los vidriados varían entre 96\% y 101\%. También se han analizado las inclusiones de las pastas y las partículas de los vidriados para obtener su composición. El sistema de microanálisis EDX se ha calibrado con óxido y patrones minerales y de vidrio para obtener resultados validados. Los límites de detección típicos fueron del 0,1\% para $\mathrm{Na}$, Mg, Al, P, K, Ca, Ti, Mn y Fe, 0,2\% para Si y Cu, $0,3 \%$ para $\mathrm{Sn}$ y $\mathrm{Sb}$ y $0,4 \%$ para $\mathrm{Pb}$.

\section{RESULTADOS ARQUEOMÉTRICOS: PASTAS, ALTERACIÓN Y TÉCNICAS DE VIDRIADO}

A continuación se incluyen los comentarios del análisis y de los datos químicos de las pastas (Tabla 2) y de los vidriados transparentes monocromos/bícromos (Tabla 3), los vidriados transparentes polícromos (Tabla 4) y los vidriados opacos (Tabla 5).

\subsection{Pastas cerámicas}

Las cerámicas del conjunto son piezas hechas a torno y la mayoría tuvieron una funcionalidad como vajilla de mesa. Las pastas de todas ellas están muy bien trabajadas y depuradas, lo que provoca que el número de inclusiones sea sensiblemente más bajo que en piezas cerámicas con otra funcionalidad, como cerámica de cocina o de almacenamiento. Esta menor presencia de inclusiones, unido a que las piezas fueron cocidas a alta temperatura, dificulta la identificación de las mismas para compararlas con el mapa geológico de la zona.

Las pastas cerámicas están compuestas de arcillas calcáreas, ricas en caliza, con contenidos de calcio que varían entre los 14-22\% CaO. Los colores de las pastas son variados y pueden ser anaranjados, beiges y grises, dependiendo de si la atmósfera de cocción fue oxidante (Figs. 6A, C) o reductora (Figs. 6B, D). En todos los casos, las cerámicas fueron cocidas a alta temperatura (por encima de $950^{\circ} \mathrm{C}$ ). La microestructura de las pastas y su composición mineralógica se caracteriza por la presencia de granos de cuarzo, feldespatos y micas biotitas (Figs. 6E, F). Otras inclusiones presentes en estas pastas son los nódulos ferruginosos de color rojo o negro y los microfósiles de tipo foraminífero. Todas estas partículas son visibles en el microscopio óptico. También destaca la presencia de porosidades alargadas paralelas a la superficie.

\subsection{El problema de los vidriados cordobeses}

Los vidriados aparecen alterados debido a los agentes externos (principalmente la humedad) durante su enterramiento. El caso de los

1. Todos los porcentajes se dan en peso del óxido. 
Tabla 2. Composición química de las pastas cerámicas cordobesas analizadas por microscopio electrónico de barrido con detector de energía dispersiva de rayos-X (SEM-EDX).

\begin{tabular}{|c|c|c|c|c|c|c|c|c|c|c|c|}
\hline VIDRIADO & MUESTRA & $\mathrm{Na}_{2} \mathrm{O}$ & MgO & $\mathrm{Al}_{2} \mathrm{O}_{3}$ & $\mathrm{SiO}_{2}$ & $\mathrm{~K}_{2} \mathrm{O}$ & $\mathrm{P}_{2} \mathrm{O}_{3}$ & $\mathrm{CaO}$ & $\mathrm{TiO}_{2}$ & $\mathrm{FeO}$ & $\mathrm{PbO}$ \\
\hline \multirow{2}{*}{$\begin{array}{l}\text { Transparente } \\
\text { Monocromo }\end{array}$} & $\mathrm{PH} 8$ & 0.6 & 2.0 & 12.9 & 53.6 & 1.7 & 2.7 & 20.0 & 0.6 & 4.8 & 1.1 \\
\hline & PH2O & 0.8 & 2.6 & 14.2 & 52.6 & 0.7 & 1.9 & 20.0 & 0.7 & 5.4 & 0.9 \\
\hline \multirow{4}{*}{$\begin{array}{l}\text { Transparente } \\
\text { Bícromo }\end{array}$} & $\mathrm{PH} 9$ & 0.7 & 2.4 & 14.7 & 52.1 & 0.8 & 2.9 & 20.2 & 0.6 & 4.9 & 0.6 \\
\hline & PH10.3 & 0.4 & 2.5 & 14.3 & 52.1 & 0.6 & 3.1 & 20.4 & 0.7 & 5.8 & 0.5 \\
\hline & PH10.1 & 0.8 & 2.0 & 13.6 & 56.6 & 2.0 & 2.3 & 15.9 & 0.7 & 5.0 & 1.1 \\
\hline & PH11.1 & 0.5 & 2.1 & 14.3 & 53.3 & 0.5 & 3.0 & 19.6 & 0.6 & 5.4 & 0.4 \\
\hline \multirow{5}{*}{$\begin{array}{c}\text { Transparente } \\
\text { Polícromo }\end{array}$} & PH11.3 & 0.4 & 2.2 & 13.4 & 54.2 & 1.6 & 3.7 & 18.4 & 0.7 & 4.9 & 1.2 \\
\hline & $\mathrm{PH} 12$ & 0.5 & 2.1 & 14.0 & 58.6 & 1.4 & 3.2 & 14.3 & 0.8 & 4.9 & 0.5 \\
\hline & PH15.2 & 0.8 & 1.9 & 13.5 & 50.3 & 1.8 & 3.0 & 21.9 & 0.7 & 4.5 & 1.2 \\
\hline & PH16 & 0.7 & 2.3 & 14.2 & 52.0 & 1.3 & 2.8 & 20.8 & 0.5 & 5.0 & 0.4 \\
\hline & $\mathrm{PH} 18$ & 0.6 & 2.4 & 14.3 & 52.9 & 0.6 & 2.7 & 20.5 & 0.6 & 5.0 & 0.5 \\
\hline \multirow{5}{*}{$\begin{array}{c}\text { Opaco con } \\
\text { estaño } \\
\text { Polícromo }\end{array}$} & PH19 & 0.5 & 2.3 & 13.8 & 52.3 & 0.5 & 3.1 & 21.6 & 0.7 & 5.0 & 0.1 \\
\hline & PH13.5 & 0.7 & 2.4 & 13.1 & 52.2 & 0.7 & 2.5 & 22.0 & 0.8 & 5.0 & 0.5 \\
\hline & $\mathrm{PH} 14 \mathrm{~B}$ & 0.7 & 2.2 & 13.9 & 54.5 & 1.6 & 2.6 & 18.8 & 0.7 & 5.1 & 0.3 \\
\hline & $\mathrm{PH} 14 \mathrm{~A}$ & 0.8 & 2.2 & 14.3 & 54.2 & 0.8 & 3.1 & 18.5 & 0.9 & 5.0 & 0.3 \\
\hline & PH50 & 1.2 & 2.4 & 13.8 & 51.5 & 1.0 & 1.9 & 20.6 & 0.7 & 5.5 & 0.5 \\
\hline
\end{tabular}

vidriados hallados en el subsuelo cordobés es uno de los peores que nos hemos encontrado en cuanto a conservación, debido a la elevada acidez del suelo. Así, en las zonas vidriadas alteradas, especialmente las superficiales, se ha perdido parte del plomo de la composición del vidriado. Este fenómeno de alteración impide analizar esas áreas, puesto que los resultados no son fiables. Asimismo, la presencia de partículas (p. ej. óxido de estaño, cuarzo, etc.) favorece su deterioro. De ahí que resulte de suma importancia seleccionar bien el área a analizar, tanto con el microscopio electrónico de barrido como con otras técnicas, para obtener resultados fiables de la composición química de los vidriados.

Las cerámicas vidriadas recuperadas del pozo cordobés se caracterizan por presentar unos vidriados algo más alterados de lo habitual, puesto que proceden de un pozo negro o letrina (MORENO et alii, 2006) y estuvieron en contacto con residuos orgánicos que habrían propiciado su meteorización, lixiviación del plomo y posterior recristalización del plomo, con la consiguiente proliferación de fosfatos y carbonatos de calcio y plomo dentro de las burbujas y de las grietas del vidriado (véanse Figs. 7F y 9C) y en la superficie del mismo, donde se formó una especie de cemento con las partículas del terreno (véanse Figs. 7C y 9F). A pesar de todo esto huelga decir que, considerando las circunstancias, la mayoría de los vidriados están relativamente bien conservados.

\subsection{Cerámica vidriada monocroma y bícroma}

Los análisis químicos de los vidriados transparentes monocromos y bícromos aparecen en la Tabla 3. Los monocromos son vidriados de plomo (47-55\% PbO), mientras que los vidriados bícromos muestran una mayor variabilidad (48-61\% PbO). Los contenidos de calcio y aluminio varían del 1,7-5,6\% CaO y del 1,1$3,5 \% \mathrm{Al}_{2} \mathrm{O}_{3}$ Los contenidos de sodio y magnesio son muy bajos en todos los casos, incluso por debajo de los límites de detección para algunas de las muestras.

Todos los vidriados muestran una interfaz pasta cerámica-vidriado mínima, 


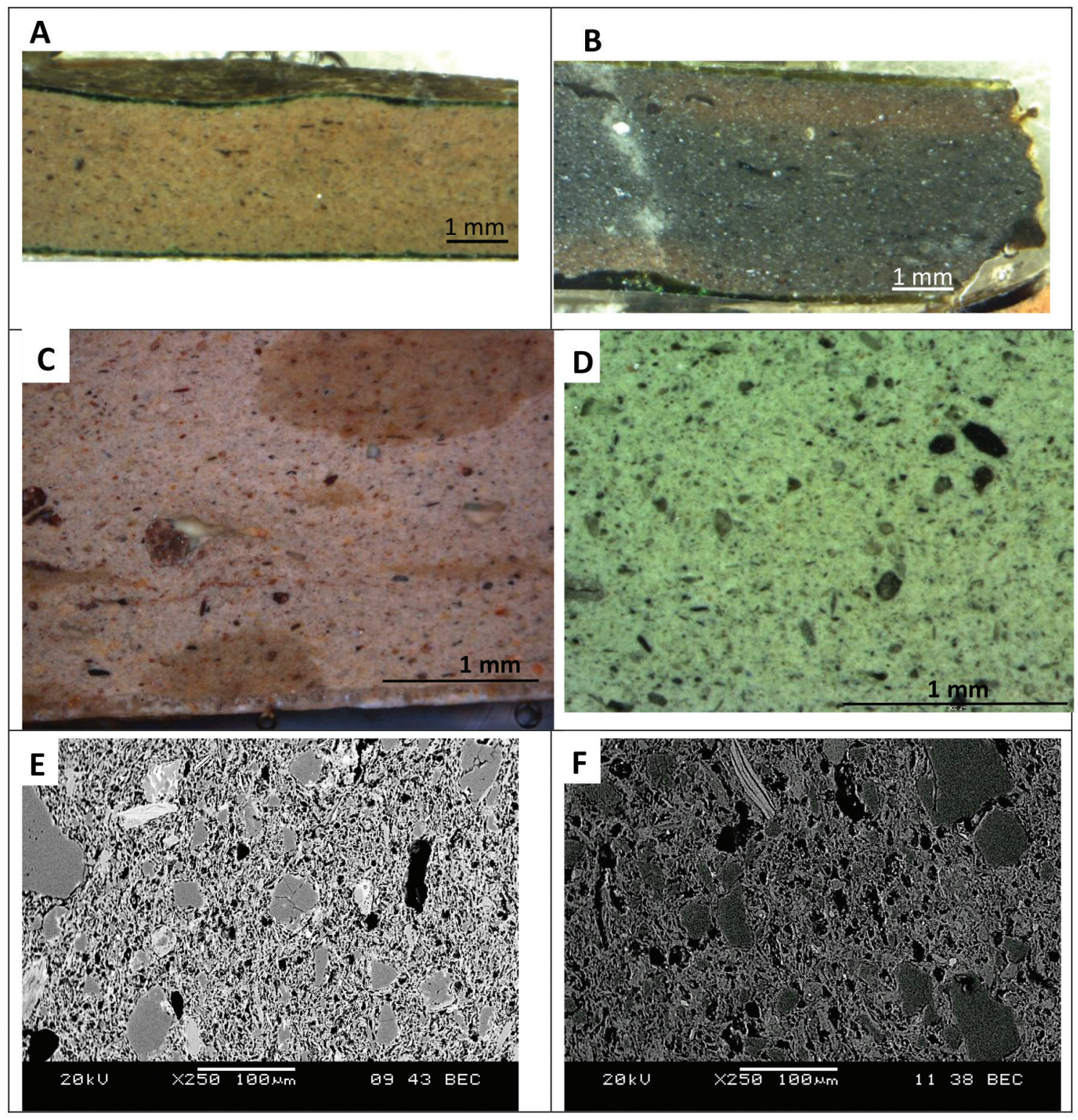

Fig. 6. Imágenes de Microscopía óptica (OM) de las pastas cerámicas calcáreas finas y compactas. (A) (PH8) y (C) (PH50) cocción oxidante; (B) (PH12) y (D) (PH20) cocción reductora. Imágenes de Microscopía electrónica de electrones retrodispersados (SEM-BSE): (E) Inclusiones de granos de cuarzo y algún feldespato (PH18) y (F) Inclusiones de cuarzo y una mica biotita (PH11.3).

pequeñas burbujas y dos tipos de grietas: las perpendiculares a la superficie, como consecuencia de las diferencias de contracción de la pasta y el vidriado durante el proceso de enfriamiento; y aquellas paralelas a la superficie, que están relacionadas con una baja temperatura de cocción o incluso con la alteración, cuando aparecen cerca de la superficie (Fig. 7C).
La composición de los vidriados monocromos es homogénea (Tabla 3): el color verde (PH8) se obtenía por la adición de cobre ( 3,5\% $\mathrm{CuO}$ ) y el color melado (PH20) por la adición de hierro (5,5\% FeO). En el caso de la pieza PH20, el vidriado melado contiene un poco de cobre ( $<1 \% \mathrm{CuO}$ ) y pequeños cristales de diópsidos. Estos cristales se formaron durante la cocción de la pieza, puesto que su contenido de 


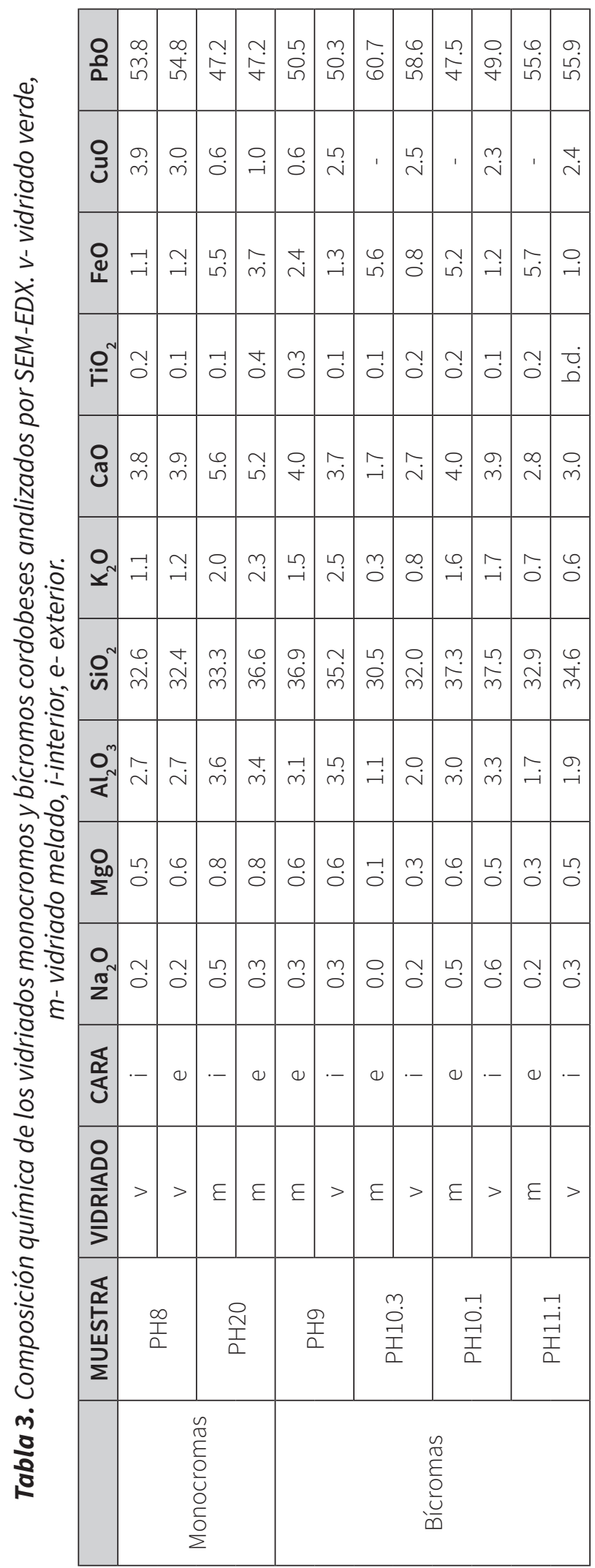


magnesio es algo más elevado que en el resto de cerámicas del conjunto. Esta pieza presenta también la peculiaridad de ser la única cerámica con decoración a molde. El grosor de los vidriados monocromos es muy variado 100$300 \mu \mathrm{m}$, aunque en ocasiones el vidriado se ha descamado, debido a la presencia de grietas paralelas a la superficie y a la alteración de los procesos postdeposicionales, y ha perdido las capas más superficiales del mismo, reduciéndose el grosor original del mismo.

Los vidriados transparentes bícromos tienen la cara exterior de color melado, conteniendo grandes cantidades de hierro (Tabla 3) (2-6\% FeO), mientras que la superficie interior es verde y contiene cobre ( $2,4 \% \mathrm{CuO})$. Tanto el cobre como el hierro están disueltos en los vidriados. En algunos casos, se encuentran algunas partículas redondeadas de óxido de hierro en los vidriados melados/marrones, como consecuencia de la adición de partículas de óxido de hierro para obtener estos colores. El grosor de los vidriados es bastante homogéneo (80-190 $\mu \mathrm{m})$ y a menudo es más grueso para la superficie vidriada en melado, como el ejemplo del cuenco PH10.3 que tiene un grosor de $190 \mu \mathrm{m}$ en la superficie exterior melada y un grosor de $90 \mu \mathrm{m}$ en la superficie interior verde (Figs. $7 \mathrm{C}$ y $7 \mathrm{~F}$ ). No se han documentado vidriados marrones compuestos de óxido de manganeso.

\subsection{Cerámica vidriada polícroma}

En el anterior artículo solo pudimos distinguir el grupo de las cerámicas polícromas siguiendo el criterio de la utilización de tres o más colores en su decoración. Sin embargo, tras los análisis arqueométricos, este grupo queda dividido en dos: transparentes y opacos.

Los análisis químicos de los vidriados transparentes polícromos aparecen en la Tabla 4. Todos los vidriados polícromos son vidriados con un alto contenido de plomo (56-67\% PbO), mayor que para los vidriados monocromos y bícromos. Los contenidos de calcio y aluminio son más bajos que para el grupo anterior
A
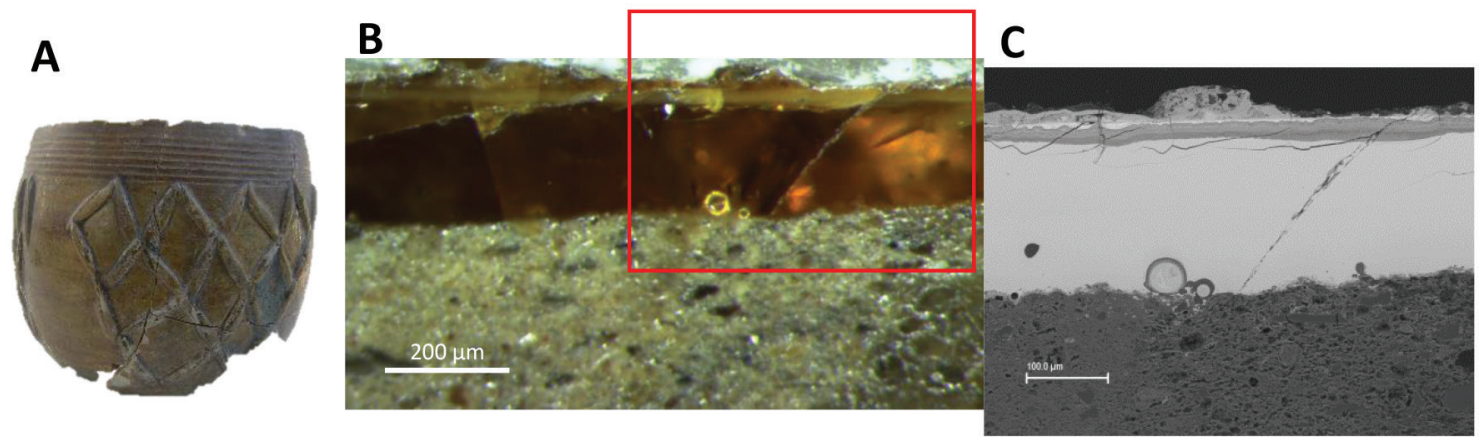

D

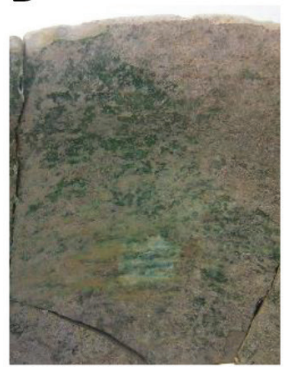

$\mathbf{E}$
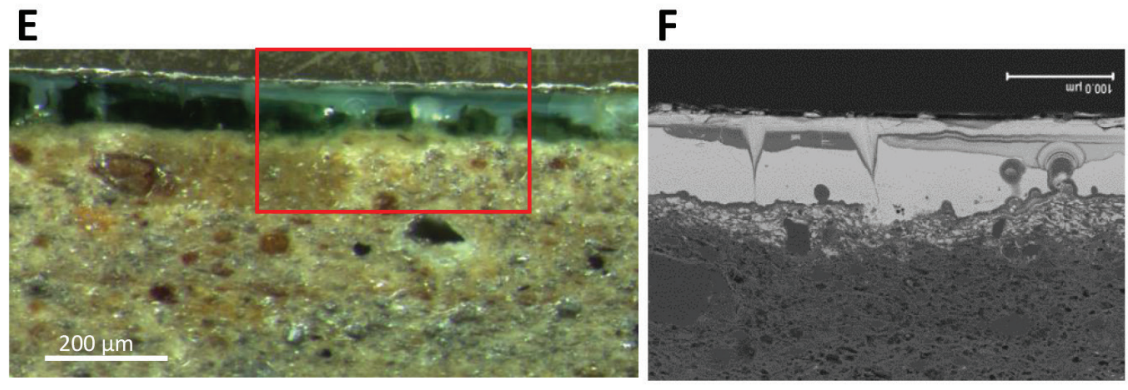

Fig. 7. Vidriado transparente bicromo (PH10.3): Imagen OM y SEM-BSE (A, B, C) cara melada y (D, E, F) cara verde. 


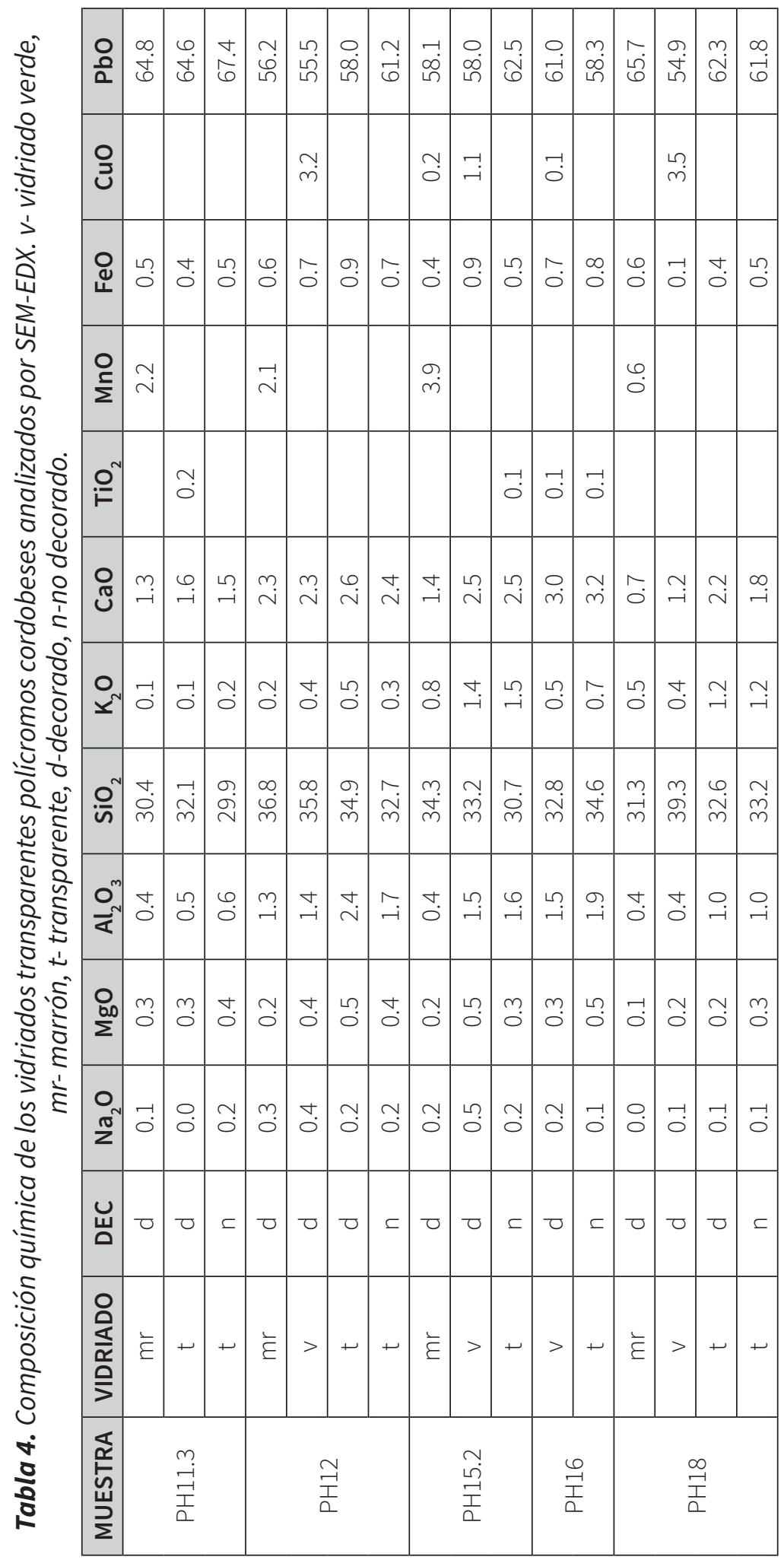


y oscilan entre $0,7-3,2 \% \mathrm{CaO}$ y $0,4-2,4 \% \mathrm{Al}_{2} \mathrm{O}_{3}$. Los contenidos de sodio y magnesio son muy bajos en todos los casos, incluso por debajo de los límites de detección para algunas de las muestras.

Los vidriados transparentes polícromos se caracterizan por la aplicación de las decoraciones en verde de cobre y marrón de manganeso y, en una de las piezas, en melado de hierro (PH18). Estas decoraciones trazan sobre un fondo vidriado de color rosado o verdoso. Este fondo varía según el color de la pasta, ya que parte de la luz se refleja en la superficie de la cerámica puesto que el vidriado es transparente: así, aparece de color rosado, cuando la pasta es anaranjada, amarillento si es crema, y color verdoso (ya que el hierro del vidriado está reducido) cuando la pasta es grisácea. Los trazos sobresalen con respecto a la cobertura del fondo porque están aplicados sobre ésta. Este efecto de relieve provoca que los trazos de colores sean más gruesos que el fondo, como puede verse incluso macroscópicamente. Este mayor grosor se consigue mezclando el colorante de óxido de plomo y cobre, hierro o manganeso con granos de cuarzo redondeados y de diferentes tamaños. Un ejemplo es el color verde de la orza PH18 que muestra grandes granos de cuarzo en el vidriado (Figs. 8A y 8C). El uso del manganeso es una novedad con respecto a las producciones previas monocromas y bícromas.

Los colores de la orza PH18 están en relieve y dispuestos como goterones o salpicaduras (Fig. 8A). Este tipo de decoración parece inspirada en los diseños de la dinastía Tang, que copian también las cerámicas abasíes (WATSON, 2004). Las superficies no decoradas son transparentes y presentan una coloración amarilla pálida-verdosa. Los vidriados son muy ricos en plomo y bastante puros, además contienen muy bajos contenidos de potasio, calcio, aluminio y hierro, en comparación con los vidriados transparentes monocromos y bícromos. El grosor de los vidriados es variable, oscila entre 120-300 um para la mayoría de los vidriados y decoraciones, siendo más gruesos en las zonas pintadas con los vidriados de color (Figs. 8A y 8B). La decoración verde de la $\mathrm{PH} 18$ es mucho más gruesa - 530 $\mu \mathrm{m}$ - debido a la presencia en el vidriado de grandes granos de cuarzo sin disolver (Fig. 8C). Esto parece intencional para conseguir un efecto "splash", o de salpicaduras, en la decoración y evitar que se difuminen los distintos colores.
A
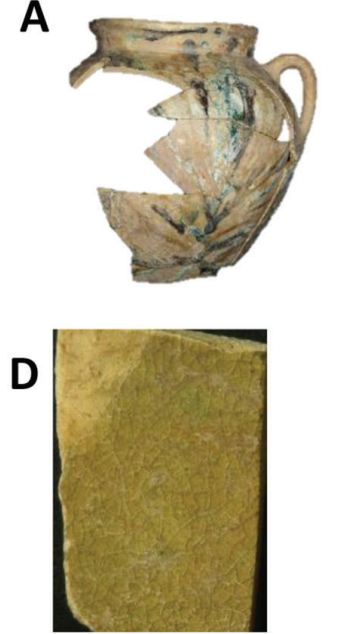

B
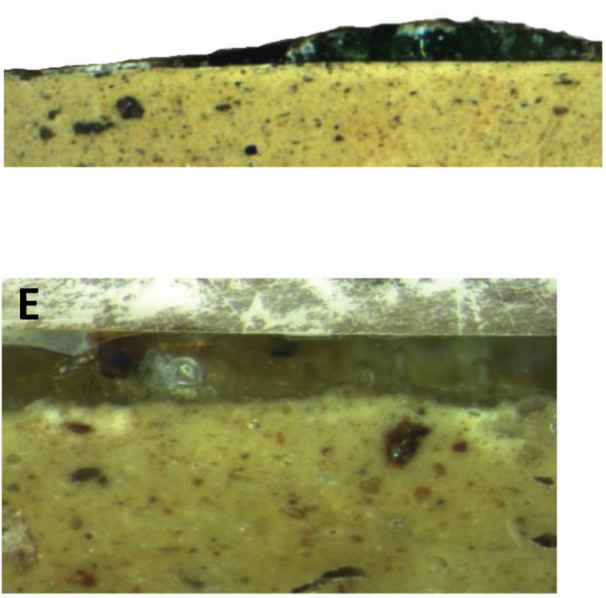

C
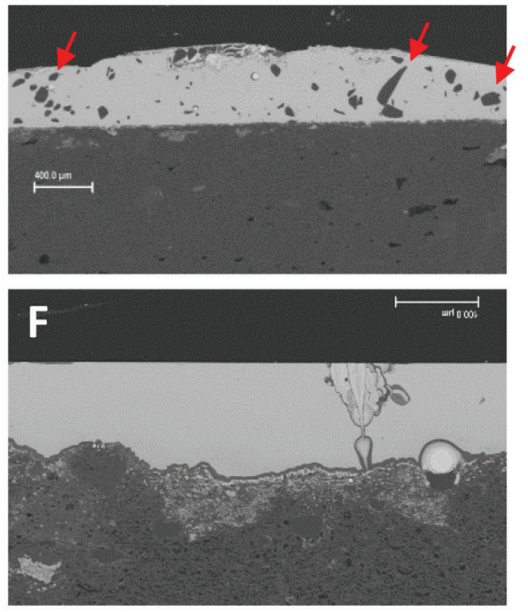

Fig. 8. Vidriado transparente polícromo (PH18). Imagen OM y BSE (B, C) cara exterior decoración verde sobrecubierta y (D, E, F) cara interior sin decorar de color verdoso. 


\subsection{Los vidriados de plomo opacifica- dos con estaño}

Estos vidriados son de tipo de plomo alcalino y contienen $36-44 \% \mathrm{PbO}, 2-4 \% \mathrm{Na}_{2} \mathrm{O}, 0,6-$ $2 \% \mathrm{MgO}, 1-2 \% \mathrm{Al}_{2} \mathrm{O}_{3}$ y $2-4 \% \mathrm{CaO}$ (ver Tabla 5). El estaño está presente con partículas muy pequeñas de casiterita, las cuales están bien distribuidas en las dos caras de las piezas vidriadas: la superficie con decoración y la no decorada (Fig. 9); los contenidos de estaño suman alrededor del $10 \% \mathrm{SnO}_{2}$, siendo ligeramente superior tanto en la superficies decoradas como en los vidriados blancos. Los colorantes usados son los mismos que para los vidriados transparentes polícromos: cobre para el verde y manganeso para el marrón/ negro (Figs. 9B y 9C). Las zonas decoradas están en relieve sobre la superficie blanca de estaño. Esto se debe a que fueron aplicadas sobrecubierta (Fig. 9A).

El grosor de los vidriados es más homogéneo en este grupo, probablemente porque la decoración se lleva a cabo mediante la pintura de motivos simples, de tipo geométrico. Aun así, existe una diferencia entre los vidriados de la superficie no decorada, que son más delgados $(125-200 \mu \mathrm{m})$ que los de las superficies decoradas $(\sim 300 \mu \mathrm{m})$. Esto es consecuencia de la aplicación de la decoración sobrecubierta.

El grupo de los vidriados opacos presenta mayores problemas de alteración y están más erosionados, con fosfatos y carbonatos de plomo y calcio cristalizando en el interior de las burbujas, en las grietas y en la capa más superficial de los vidriados, actuando como cemento de las partículas que están presentes en el terreno durante la fase postdeposicional (Fig. 9F). Otro efecto de la degradación de los vidriados es que tienen un color mate y aspecto pulvurulento debido a la presencia de partículas de casiterita, de carbonatos y fosfatos de plomo y calcio, que actúan de cemento adhiriendo tierra del entorno, lo que provoca que la superficie tenga un color blanco o amarillento mate y no brillante. (Figs. 9D y $9 \mathrm{E})$.

\section{INTERPRETACIÓN}

Con el objetivo de comparar las composiciones base de los vidriados, y teniendo en cuenta que las cantidades de colorantes añadidos eran variables (como hemos visto en el apartado 4), hemos quitado los colorantes y renormalizado los resultados de la composición de los vidriados. Los colorantes identificados en los vidriados cordobeses son cobre, hierro y manganeso. Un factor que hay que tener en cuenta es que, aparte de la cantidad extra de óxido de hierro que era añadido a los vidriados melados y marrones, una parte del hierro estaría presente también en el vidriado transparente, pero no en cantidades importantes. Una vez recalculados, las composiciones químicas de los vidriados base pueden ser comparados. En la figura 10 pueden verse los vidriados renormalizados $\mathrm{CaO}+\mathrm{K}_{2} \mathrm{O}+\mathrm{Al}_{2} \mathrm{O}_{3}{ }^{*}$ versus $\mathrm{PbO}^{*}$. En relación a las producciones de vidriados transparentes de plomo se han constatado algunas diferencias entre los vidriados monocromos/bícromos y los polícromos. El primer grupo se caracteriza por una mayor cantidad de hierro, potasio, aluminio y calcio y, en menor medida, de sodio y magnesio. Estos contenidos más altos parecen estar asociados a una mayor cantidad de arcilla en la receta del vidriado, es decir, serían vidriados menos puros (proporción eutéctica plomo-silicio 70\% $\left.\mathrm{PbO}-30 \% \mathrm{SiO}_{2}\right)$. Sin embargo, esto no quiere decir que la arcilla de la pasta fuera disuelta durante la cocción del vidriado, considerando que no hay relación entre la cantidad de calcio contenido en la pasta cerámica y la cantidad de calcio disuelto en el vidriado. Por tanto, la opción de que el óxido de plomo se aplicaba directamente sobre la pasta o que estas piezas fueran monococción, queda descartada. De hecho, en otros estudios de vidriados andalusíes a partir de evidencias arqueológicas procedentes de talleres alfareros, se ha demostrado que los vidriados de plomo se fritaban en al-Andalus antes de aplicarse en la superficie cerámica. En los talleres de Pechina y Murcia se encontraron "ollas", o contenedores con forma de ollas pero con diferente funcionalidad, que tenían su cara interna recubierta por 


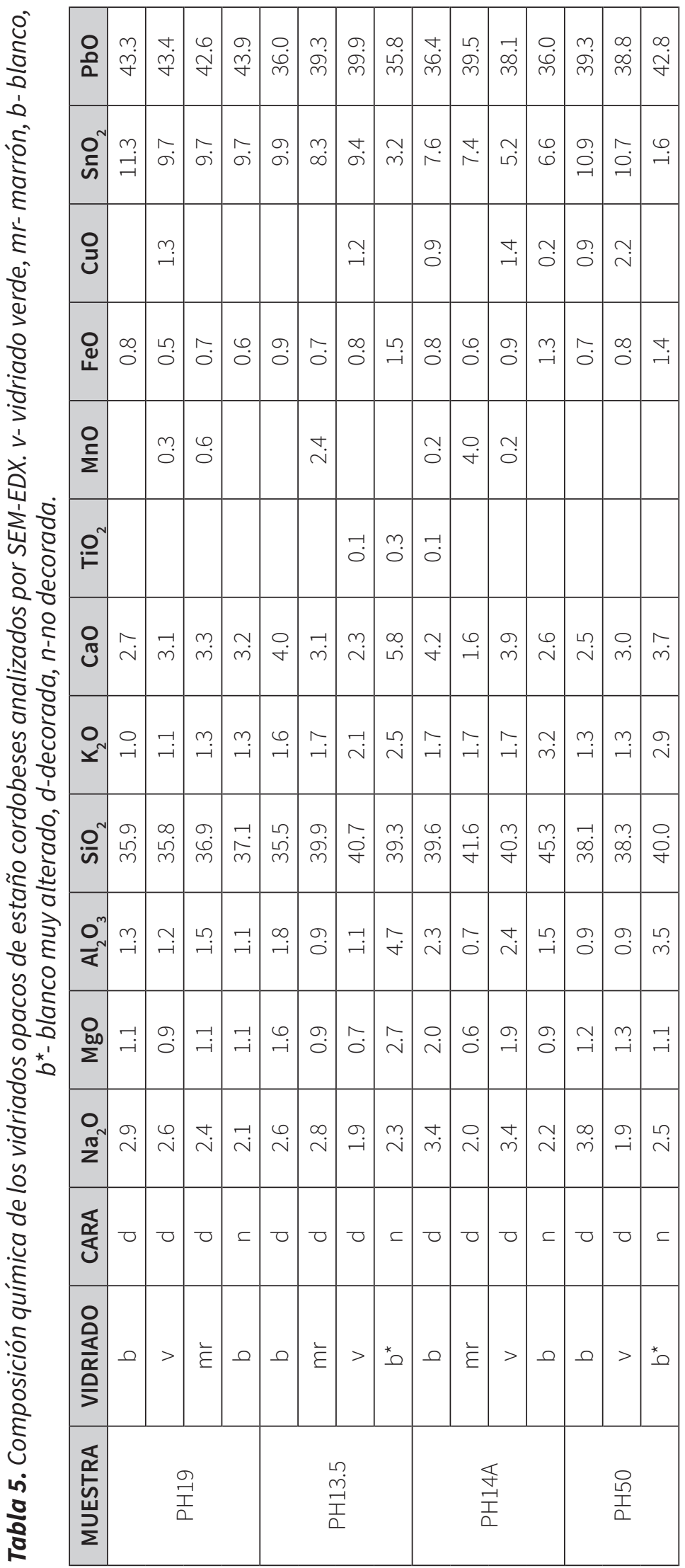




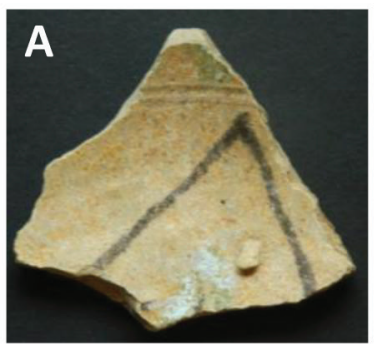

B
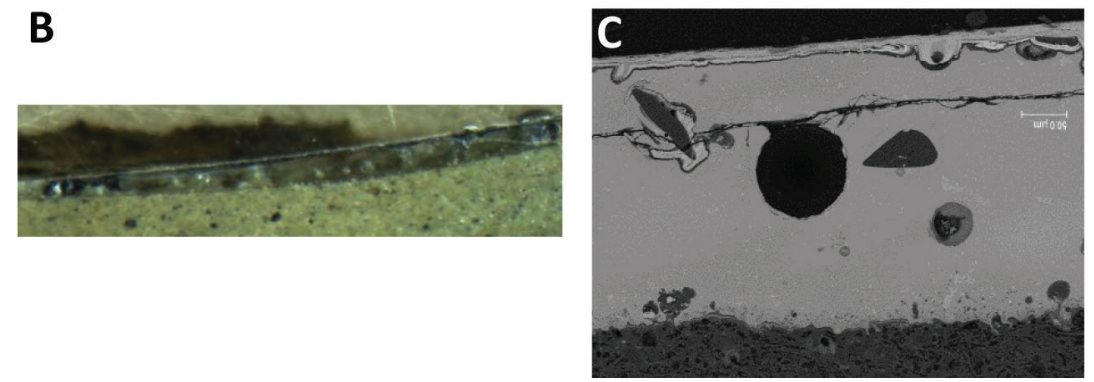

D

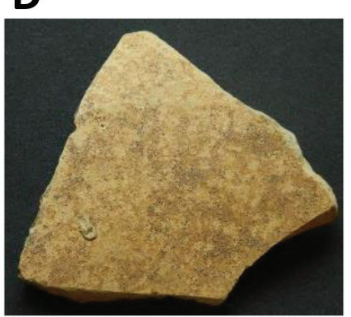

E

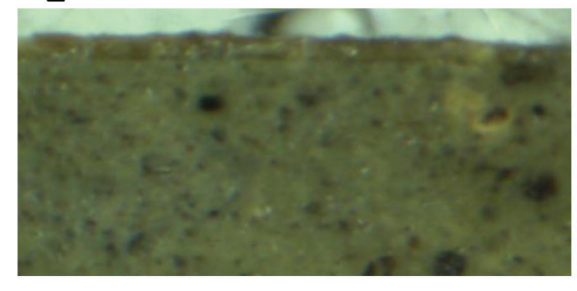

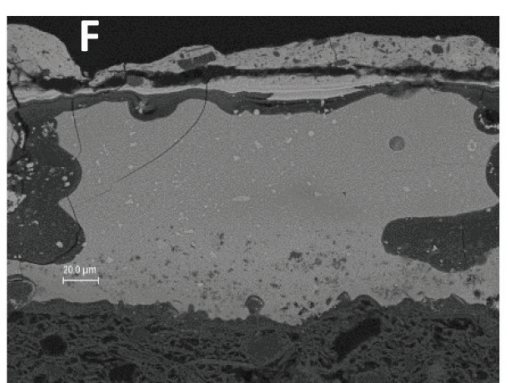

Fig. 9. Cerámica opacificada con estaño (PH14): (A) cara decorada en verde y marrón, (B) imagen OM del vidriado marrón, (C) imagen BSE del vidriado marrón con cristales de casiterita en blanco, (D) cara exterior blanca sin decorar, (E) imagen OM del vidriado blanco, (F) imagen BSE del vidriado blanco con cristales de casiterita y una capa de alteración en la parte superior del vidriado.

una capa protectora de arcilla rica en aluminio y calcio. En ocasiones, sobre esta capa protectora había una capa de vidriado. Los análisis demostraron que una mezcla de arena y óxido de plomo fue fundida en su interior (MOLERA et alii, 2009; SALINAS et alii, 2019a). Como consecuencia de este proceso, la frita obtenida era más rica en calcio y aluminio. Posteriormente, la frita era molturada y mezclada con agua, las cerámicas eran sumergidas en esta mezcla e introducidas en el horno para que se cociera el vidriado. Los vidriados son bastante homogéneos y no contienen precipitados cristalinos. El grupo de los vidriados monocromos y bícromos que contienen más calcio y aluminio son consistentes con este procedimiento de fabricación y aplicación del vidriado.

Por el contrario, los vidriados base de los polícromos son muy puros y contienen bajas cantidades de hierro, aluminio, potasio y calcio, y también de sodio y magnesio, además de ser ricos en plomo y muy transparentes (Fig. 10). Esta composición, unida a la presencia de granos de cuarzo sin disolver (Fig. 8C), sugiere que se realizó una mezcla de óxido de plomo y arena para la producción de estos vidriados.
Que los transparentes polícromos sean más puros parece responder a una opción técnica voluntaria para evitar que el fondo tenga color. Así, sin hierro, consiguen que los colores del fondo no sean intensos, con la intención de imitar a las cerámicas vidriadas blancas opacas. Estos vidriados transparentes polícromos son delgados y cubren toda la superficie cerámica. A la misma mezcla de vidriado base se le añadió el óxido de cobre, hierro o manganeso y, con el colorante resultante, se pintó la decoración sobre el vidriado transparente.

El tercer grupo, el de los vidriados de estaño, es muy diferente y pertenece a otra tecnología (Fig. 10). No solo por la presencia de estaño, sino también por los altos contenidos de sodio, magnesio y aluminio. Estos contenidos más elevados son típicos de las cenizas vegetales y sugieren la adición de plantas sódicas en la mezcla del vidriado. Este ingrediente aparece nombrado en los tratados orientales para la producción de vidriados blancos opacos de estaño (MATIN et alii, 2018) y confirma que los vidriados de estaño se obtenían de la mezcla de plomo y estaño y que eran calcinados/oxidados junto con arena 

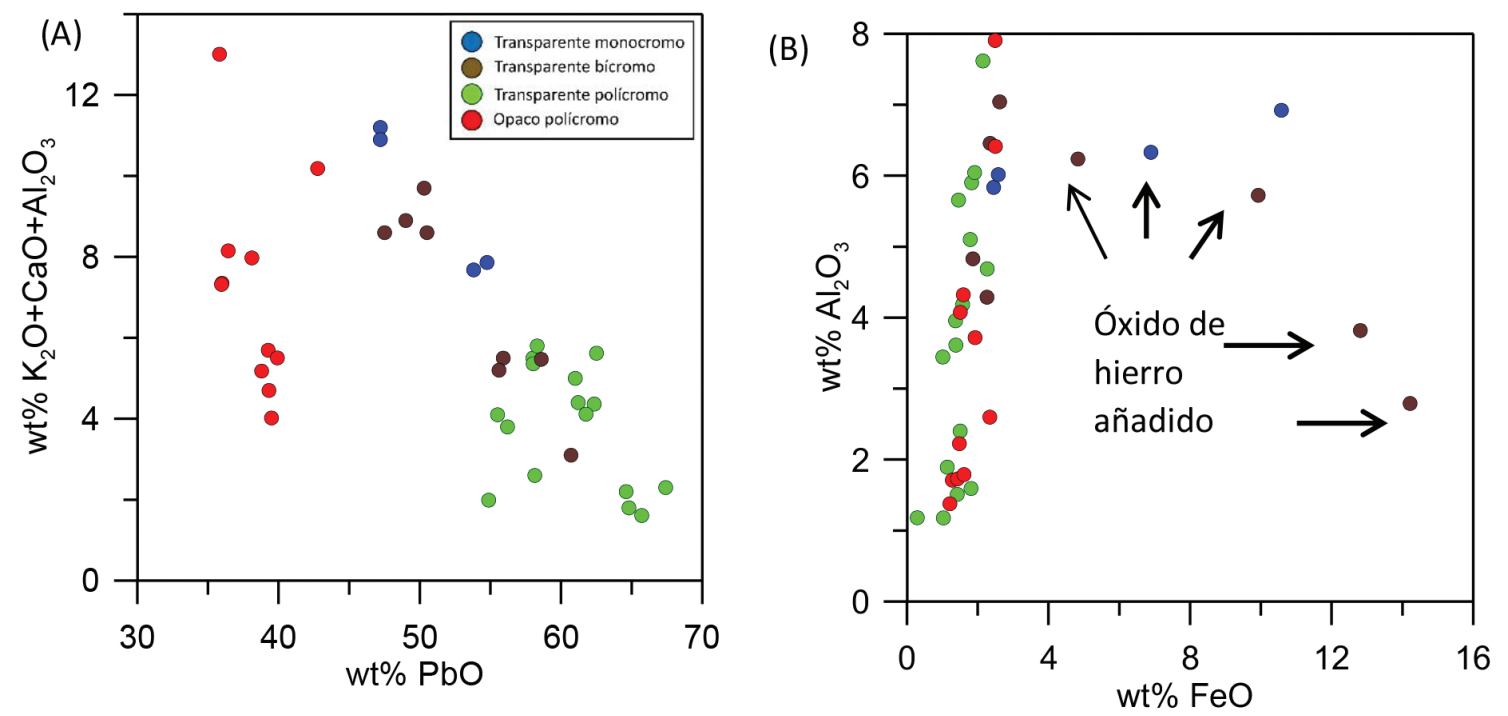

Fig. 10. Diagramas gráficos de la composición química de los vidriados de la Posada de la Herradura: transparente monocromo (en azul), transparente bícromo (marrón), transparente policromo (verde) y opaco polícromo (rojo). A) $\mathrm{K}_{2} \mathrm{O}+\mathrm{CaO}+\mathrm{Al}_{2} \mathrm{O}_{3}$ versus $\mathrm{PbO}$ y B) $\mathrm{Al}_{2} \mathrm{O}_{3}$ versus FeO.

y plantas sódicas. Otra peculiaridad de los primeros vidriados de estaño andalusíes es que los vidriados de colores fueron aplicados sobre el vidriado blanco opaco, siguiendo la misma técnica que los vidriados transparentes polícromos. Los vidriados del grupo de estaño son mucho más pobres en hierro, alineándose con los transparentes polícromos, y alejándose de los monocromos y los bícromos. Esto se debe a que los vidriados polícromos, tanto opacos como transparentes, quieren conseguir fondos blancos, sin contaminación de óxidos de hierro que modifiquen esa tonalidad.

En resumen, este conjunto nos demuestra que tres tecnologías diferentes coexistieron, al menos durante un corto periodo de tiempo. Los vidriados monocromos y bícromos serían una continuación de las primeras producciones vidriadas. Y los vidriados transparentes polícromos y blancos opacos corresponden a una tecnología completamente nueva, puesto que los vidriados blancos opacos monocromos no fueron producidos en al-Andalus en ese momento, al contario que ocurre en tierras islámicas orientales. El conjunto vidriado de la Posada de la Herradura presenta una gran variedad de formas (ataifores, cuencos, jarritos, vasos, orzas y candiles) que pertenecen en su mayoría al servicio de mesa. Un rasgo común a todas las piezas es la ausencia de pies, tanto en los ataifores como en otras formas. Esta es una diferencia significativa con respecto a las cerámicas vidriadas contemporáneas de otros territorios islámicos en los que la presencia de formas con pie es una constante. Otra característica del conjunto es la variedad de técnicas decorativas utilizadas (incisa, aplicada, a molde, pintada) y la simpleza de los diseños decorativos, principalmente motivos geométricos.

\subsection{Buscando conexiones}

En el artículo previo intentamos encontrar las conexiones de las cerámicas vidriadas andalusíes y otros territorios islámicos. Para ello nos basamos principalmente en las formas, colores y decoraciones. Ahora, gracias a los datos químicos de los vidriados, podemos compararlos con los análisis de otras producciones vidriadas tempranas. Además, hemos ampliamos el marco comparativo a vidriados peninsulares previos a la etapa islámica y a los vidriados bizantinos e italianos. 


\subsubsection{Los primeros vidriados peninsulares, los vidriados bizantinos y los vidriados italianos altomedievales}

Los primeros vidriados constatados arqueológicamente en la península ibérica datan de época romana y son vidriados transparentes de plomo. Se han propuesto varios centros productores peninsulares, aunque no existen evidencias arqueológicas firmes que lo corroboren, apuntando para la mayoría de los ejemplares identificados una procedencia itálica (MORILLO, 2017: 414-422). La forma de producción de estos primeros vidriados de plomo difiere de la utilizada en época medieval, puesto que los primeros se fabricaban añadiendo óxido de plomo directamente sobre la pieza o mezclándolo con granos de cuarzo (dióxido de silicio) y aplicándolo sobre la superficie cerámica (WALTON, 2004: 119), mientras que los primeros vidriados andalusíes se obtenían mediante un proceso mucho más complejo, por el cual se preparaba una frita de óxido de plomo y granos de cuarzo en unos recipientes tipo ollas. La mezcla resultante se trituraba y se aplicaba sobre la pieza bizcochada (SALINAS et alii, 2018).

Por otro lado, la tradición vidriada peninsular desaparece en época tardoantigua y altomedieval. No existe, por el momento, constancia de que en época visigoda se produjera cerámica vidriada. De hecho, algunas supuestas cerámicas vidriadas datadas en dicho periodo han sido recientemente interpretadas como cerámicas con vidrio, relacionadas con la producción de vidrio y no de vidriado (AMORÓS y GUTIÉRREZ, en prensa; PEÑA et alii, en prensa).

No ocurre lo mismo en otros lugares del Mediterráneo donde la tecnología del vidriado pervivió, como es el caso de la producción vidriada bizantina. De hecho, en el Tolmo de Minateda se ha documentado un fragmento de cerámica vidriada en un contexto visigodo de los siglos VII-VIII, que ha sido identificada como una producción bizantina tipo "Glazed White Ware I” (AMORÓS, 2018: 271). Este hallazgo demostraría la llegada de importaciones vidriadas a la Península, consideradas como objetos de lujo, previas al inicio de la producción de cerámica vidriada andalusí.

Al igual que llegaron piezas vidriadas bizantinas, podría plantearse la posibilidad de que se diera una transmisión tecnológica del vidriado desde el mundo bizantino. De hecho, los vidriados transparentes y monocromos lisos ya se usaban ampliamente en el Imperio Bizantino desde comienzos del siglo VII y eran ricos en plomo (FRANÇOIS, 2005). Sin embargo, esta posible conexión ha sido descartada porque la forma de producirlos difiere. Se han llevado a cabo algunos análisis de vidriados bizantinos procedentes de Constantinopla (Turquía) y Lakeidamon (Grecia) que han sido datados entre los siglos IX y X y, por tanto, son contemporáneos a nuestras piezas (WALTON, 2004). Los datos han sido incluidos en la figura 11 y comparados con los vidriados cordobeses. Vemos que tres de ellos son más ricos en aluminio y más pobres en calcio. Esto es debido a que se disuelve más pasta en el vidriado como consecuencia de una forma de producción del vidriado diferente, que comprendía la aplicación del vidriado sin fritar sobre la pasta y la monococción.

Otro posible vínculo que ha sido explorado es el de las producciones vidriadas italianas altomedievales, como la conocida como "Forum Ware" (datada entre los siglos VIII al X) (WALTON, 2004) y la vetrina pesante de los siglos IX-X (TESTOLINI, 2018), herederas de los vidriados romanos y bizantinos. Sin embargo, tanto la forma diferente de producción del vidriado como la composición química de estas producciones nos ha hecho descartar esta vía de transmisión tecnológica. En concreto, las cerámicas italianas son monococción, mientras que las andalusíes (al menos las cordobesas y las pechineras) son doble cocción. Si nos fijamos en la comparativa de la figura $11 \mathrm{~A}$, donde se han incluido los análisis de tres piezas de vetrina pesante halladas en Sicilia (TESTOLINI, 2018) y dos "Forum Ware" de Roma (WALTON, 2004), vemos de nuevo cómo las italianas son más ricas en aluminio y algo más pobres en contenidos de calcio como 
consecuencia de la disolución de parte de la pasta en el vidriado.

Todos estos argumentos nos han hecho descartar estas conexiones tecnológicas y, como consecuencia, que nos centráramos en buscar las conexiones con centros productores del mundo islámico.

\subsubsection{Los primeros vidriados islámicos de Oriente y Norte de África}

La tecnología del vidriado islámico surgió antes en las tierras orientales, como

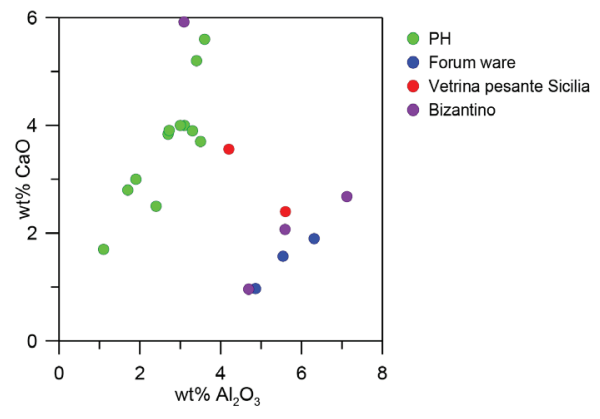

Fig. 11. Diagrama gráfico de la composición química de los vidriados transparentes de plomo CaOversus $\mathrm{Al}_{2} \mathrm{O}_{3}$ de la Posada de la Herradura (PH) (en verde), comparando con vidriados "Forum Ware" (en azul oscuro) (WALTON, 2004), Vetrina pesante (en rojo) (TESTOLINI, 2018) y Bizantinos (en morado) (WALTON, 2004).

lo demuestran los hallazgos en el Próximo y Medio Oriente (NORTHEDGE y KENNET, 1994) y en el Levante mediterráneo, en las actuales Palestina ${ }^{2}$ (TAXEL, 2014), Jordania (WHITCOMB, 1989) y Siria (MCPHILLIPS, 2012), y en Egipto (GAYRAUD y VALLAURY, 2017). Son varias las tecnologías que conviven desde finales del siglo VIII/principios del IX: vidriados alcalinos y de plomo, monocromos y bícromos, vidriados transparentes de plomo polícromos y vidriados de estaño. Lo que demuestra que en esta parte de la Dar al-Islam existía una red de comunicaciones y distribución bien establecida, a la vez que un mercado que demandaba este tipo de producto. Un fenómeno que llegó a las regiones occidentales, como al-Andalus, posteriormente.

Los primeros vidriados transparentes $y$ monocromos lisos producidos en el mundo islámico eran de color verde o turquesa y fueron una continuación de la tradición Sasánida (NORTHEDGE, 1997; WATSON, 2004). En al-Andalus, en época tardoemiral y primocalifal, además de la producción de vidriados monocromos verdes cordobeses, se produjeron cerámicas vidriadas en verde y melado en Pechina (CASTILLO y MARTíNEZ, 1993) y melado y marrón chocolate en Malaga (Î̃NlGUEZ y MAYORGA, 1993), sin que se hayan identificado vidriados turquesa de época emiral. También se han identificado vidriados de plomo verdes y melados en la Vega de Granada (MOLERA et alii, 2017), con una composición similar a los vidriados de plomo transparentes cordobeses. En la figura 12 se ha representado la composición química de los vidriados del alfar de Pechina (SALINAS et alii, 2019a) y de varios yacimientos de Córdoba: además de la Posada de la Herradura se incluyen los de las excavaciones arqueológicas de M- Auxiliadora (CÁNOVAS, 2006; CÁNOVAS y SALINAS, 2010) y del barrio alfarero del Zumbacón (LARREA, 2008). En todos ellos se ve una cierta correlación porque estaban utilizando la misma receta de vidriados ricos en plomo, mezclados con granos de cuarzo (silicio) y fritados antes de su aplicación sobre la cerámica bizcochada. Sin embargo, se aprecian algunas diferencias: en general, los vidriados producidos en Pechina son más ricos en plomo y sodio que los del Zumbacón. Por otro lado, los del alfar del Zumbacón de Córdoba tienen mayor variabilidad debido a que se han analizado algunas piezas defectuosas en las que el contenido de plomo se ha perdido parcialmente.

Las cerámicas vidriadas halladas en la Posada de la Herradura y las de Má-Auxiliadora

2. Cuando nos refiramos a los territorios del periodo islámico se seguirá la forma anglosajona de citar los países actuales. 
son más parecidas a las de la zona alfarera del Zumbacón que a las pechineras y, por tanto, compatibles con una producción local. Si bien es cierto que los vidriados monocromos y bícromos de la Posada de la Herradura son algo más ricos en plomo y sodio que otras cerámicas cordobesas. Esto podría deberse a que son piezas de mayor calidad que las halladas en otros conjuntos cordobeses; o también, a que fueron fabricadas en otro taller local diferente al identificado en la zona alfarera del Zumbacón, a partir de los defectos de cocción.

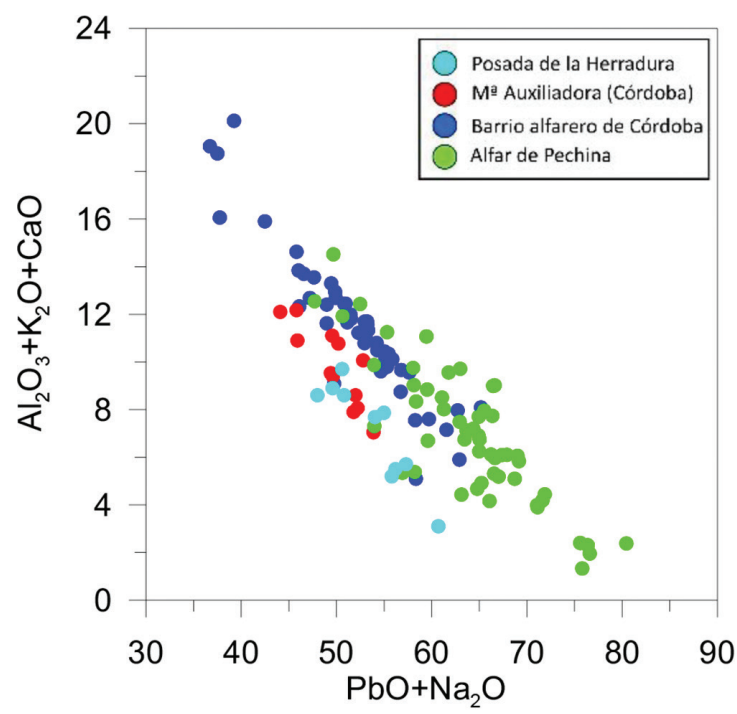

Fig. 12. Diagrama gráfico de la composición química de los vidriados transparentes mono/ bicromos $\mathrm{Al}_{2} \mathrm{O}_{3}+\mathrm{K}_{2} \mathrm{O}+\mathrm{CaO}$ versus $\mathrm{PbO}+\mathrm{Na}_{2} \mathrm{O}$ de la Posada de la Herradura (PH) (en azul claro), comparando con la excavación de Ma Auxiliadora, Córdoba (en rojo), el barrio alfarero de Córdoba (en azul oscuro) y el alfar de Pechina (en verde). Todos los lugares están situados en la Figura 1.

Respecto a las formas cerámicas y las decoraciones, encontramos ejemplares similares a los hallados en el pozo de la Posada de la Herradura en otros enclaves cordobeses (p. ej. Ma Auxiliadora) y en el alfar del Zumbacón. Es el caso de los vasos con decoración de hilos aplicados. Este tipo de forma y decoración es típica local, sin que encontremos, por el momento, indicios de fabricación en otros centros productores andalusíes.
Hemos elaborado también otro diagrama gráfico (Fig. 13) con los análisis de las pastas cerámicas de las mismas piezas vidriadas de los cuatro yacimientos arqueológicos comparados en la figura anterior para obtener más datos sobre una supuesta manufactura local de las piezas de la Posada de la Herradura. En el diagrama se aprecia claramente cómo la composición de los vidriados de Ma - Auxiliadora coincide con los de la zona alfarera del Zumbacón, mientras que los vidriados de la Posada de la Herradura se separan un poco (cuatro de ellos), aunque son compatibles con una producción cordobesa y no con una producción pechinera. De hecho, las cerámicas del taller de Pechina conforman un grupo bastante homogéneo, caracterizado por unos contenidos más altos de calcio, magnesio, aluminio y sodio, que los otros tres conjuntos representados ¿Qué conclusiones podemos extraer de esto? Parece que en Córdoba habría más de un taller funcionando a finales del emirato $y$, quizás, este pudo estar ubicado en otro sector de la ciudad. Otra posibilidad es que estos conjuntos cordobeses no sean estrictamente contemporáneos en el tiempo, es decir, que exista una diferencia de años, en los que las canteras utilizadas para aprovisionarse de arcilla no sean las mismas y/o la receta utilizada para la fabricación del vidriado haya evolucionado/ cambiado ligeramente. En cualquier caso, sí parece mantenerse la tesis de una producción local para las cerámicas vidriadas objeto de este estudio.

Los vidriados transparentes con un alto contenido de plomo y polícromos, similares a los vidriados polícromos cordobeses, fueron manufacturados por los alfareros bizantinos (ARMSTRONG et alii, 1997). En una etapa temprana del periodo islámico, los alfares de Raqqa fabricaron vajilla de mesa con una diversidad de formas, a menudo con pie, tanto vidriadas de varios colores como sin vidriar, y con vidriados de plomo, alcalinos y de estaño. Estos talleres tempranos estuvieron funcionando presumiblemente entre el 796 y 809, cuando el califa Harun al-Rashid movió la capital abasí a Raqqa, donde construyó varios palacios (FRANÇOIS y SHADDOUD, 2013; WATSON, 1999; 


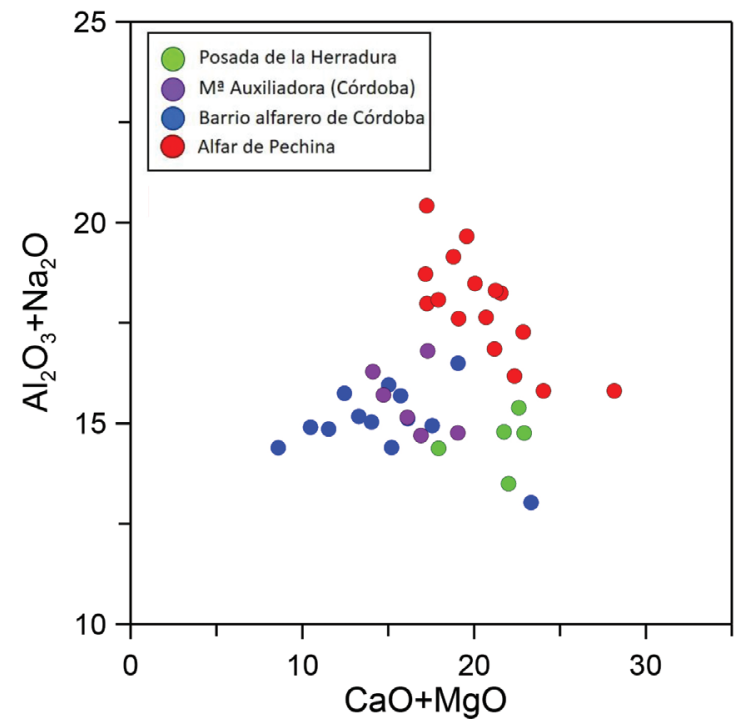

Fig. 13. Diagrama gráfico de la composición química de las pastas cerámicas de los vidriados mono/bicromos $\mathrm{Al}_{2} \mathrm{O}_{3}+\mathrm{Na}_{2} \mathrm{O}$ versus $\mathrm{CaO}+\mathrm{MgO}$ de la Posada de la Herradura (en verde), comparando con la excavación de Ma - Auxiliadora, Córdoba (en morado), el barrio alfarero de Córdoba (en azul oscuro) y el alfar de Pechina (en rojo). Todos los lugares están situados en la Figura 1.

2014). Formas similares vidriadas se encuentran también en conjuntos contemporáneos de Palestina (TAXEL, 2014) y Egipto (GAYRAUD y VALLAURY, 2017). En el Mediterráneo central, en Ifríqiya (Túnez) se produjo una vajilla de mesa polícroma transparente con decoración bajocubierta y fondo amarillo, que según algunos autores tendría influencia iraní, a la vez que un sustrato local bereber en algunos temas decorativos (GRAGUEB, 2017). Este tipo de vajilla vidriada comenzó a producirse en época aglabí, en Raqqāda a partir del 876 d.C. (BEN AMARA et alii, 2001) y tuvo continuidad en el siglo $X$, durante el periodo fatimí (BEN AMARA et alii, 2005). Otros territorios cercanos, como Tahert-Tagdempt (Algeria) (DJELLID, 2011) y Palermo (Sicilia) (ARDIZZONE et alii, 2017), estuvieron bajo la esfera de la influencia política y también tecnológica de los Aglabíes, llegando a convertirse en centros productores de vajilla vidriada polícroma. Durante algún tiempo se planteó una posible conexión tecnológica entre el territorio norteafricano y al-Andalus. Si bien las diferencias son claras. La vajilla tunecina temprana reproduce formas carenadas con pie con vidriados de plomo transparente de color amarillo, y diseños elaborados pintados bajocubierta en marrón y verde (DAOULATLI, 1994). Por el contrario, las cerámicas vidriadas cordobesas tienen formas exvasadas y no tienen pie y las decoraciones están aplicadas sobrecubierta. Además, la composición de los vidriados transparentes polícromos tunecinos es diferente a la de los vidriados cordobeses, que son muy ricos en plomo y muy puros. Los vidriados tunecinos tienen un contenido más bajo de plomo (20-30\% PbO) porque son de tipo alcalino, "lead-alkali”, y en su receta se han utilizado cenizas sódicas, mientras que los vidriados cordobeses son vidriados ricos en plomo, "high-lead", (Fig. 14). A pesar de ser producciones contemporáneas, de finales del siglo IX-principios del siglo X, están siguiendo recetas diferentes, lo que nos habla de transmisiones diferentes en la tecnología del vidriado. Otra diferencia son los contenidos de hierro y aluminio, que está relacionada con la adición o no de óxidos de hierro, ricos en aluminio, para conseguir un fondo amarillo o neutro. La producción cordobesa de vidriados de plomo transparentes y decorados con tres o cuatro colores no parece que tuviera una gran repercusión ni se alargara en el tiempo. Sí se han documentado algunas cerámicas más con vidriados transparentes polícromos en otros enclaves cordobeses, como el Alcázar o la zona alfarera del Zumbacón, pero no se han analizado.

La vajilla vidriada con estaño alcanzó su cénit durante los siglos IX y X en el Próximo y Medio Oriente, con el distintivo estilo "Samarra", característico del mundo Abasí, que incluía vidriados blancos monocromos o decorados en verde y/o azul (NORTHEDGE, 1997; WOOD et alii, 2009). Asimismo, se manufacturaban cerámicas decoradas y opacificadas con estaño, como las piezas decoradas en verde y marrón sobre fondo blanco de estaño que han sido documentadas en Raqqa, Siria (WATSON, 1999; 2014; FRANÇOIS y SHADDOUD, 2013). Los análisis de estos vidriados muestran una composición similar a los vidriados opacificados con estaño cordobeses, lo que estaría indicando que usaron una receta similar, 
(A)

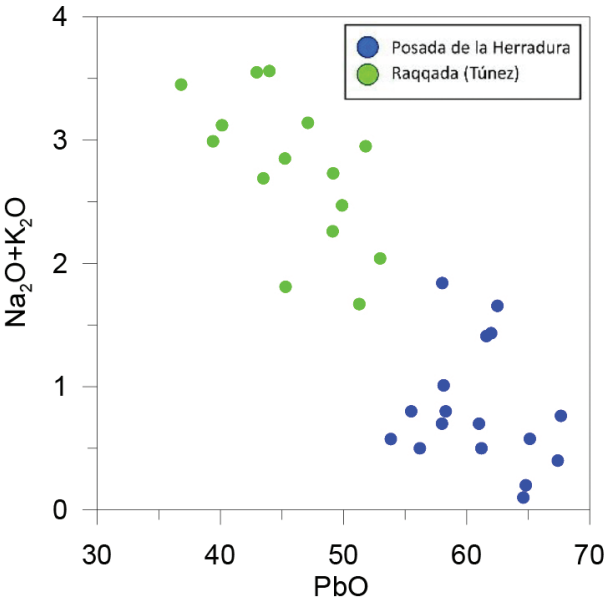

(B)

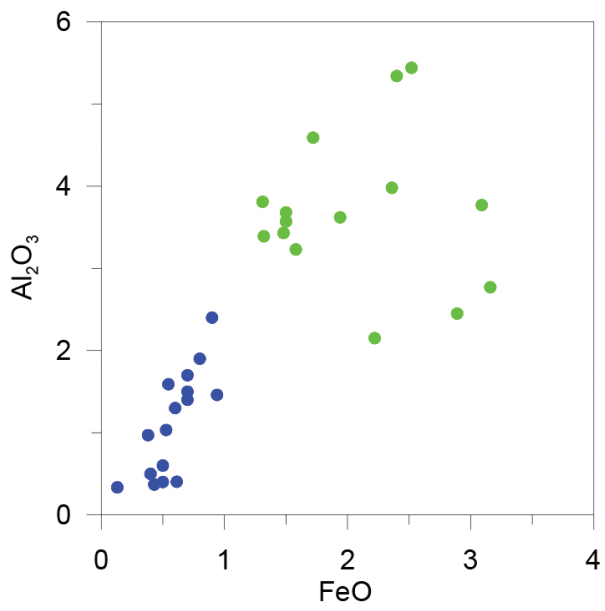

Fig. 14. Diagramas gráficos de la composición química de los vidriados transparentes policromos comparando Posada de la Herradura (PH) (en azul) y Raqqada (Túnez) (en verde). A) $\mathrm{Na}_{2} \mathrm{O}+\mathrm{K}_{2} \mathrm{O}$ versus $\mathrm{PbO}$ y B) $\mathrm{Al}_{2} \mathrm{O}_{3}$ versus $\mathrm{FeO}$.

mezclando óxido de plomo y de estaño con cenizas vegetales (MATIN et alii, 2018).

Sin embargo, en el Mediterráneo Central parece que la asimilación de la tecnología del estaño fue más tardía. Así, la evidencia más temprana de vidriados de estaño documentada hasta el momento en Ifrīqiya, la actual Túnez, parece coexistir con una producción local de loza dorada en Sabra al-Mansūriyya y tendría una datación aproximada de finales del siglo X-mediados del siglo XI (CRESSIER y RAMMAH, 2007; WAKSMAN et alii, 2014). Esto refrenda la hipótesis de que la tecnología del estaño llegaría a Ifrīqiya después de que los Fatimíes conquistaran Egipto, es decir post-972 d.C. (SALINAS et alii, 2019b), en un momento posterior al inicio de la tecnología del vidriado de estaño en al-Andalus que, gracias al conjunto cerámico de la Posada de la Herradura sabemos que comenzó antes del año 929, y, por tanto, anterior a la instauración del Califato de Córdoba. Esto es importante porque durante mucho tiempo se ha pensado que esta tecnología se iniciaba en el periodo califal, pero, en realidad, comenzó a utilizarse en al-Andalus en época tardoemiral. En la Vega de Granada, se han encontrado otros vidriados opacos polícromos que han sido datados en el periodo Emiral (MOLERA et al, 2017). Estas cerámicas también fueron decoradas sobre cubierta, como las cordobesas. Sin embargo, como en el caso de las cerámicas verde y manganeso califales, presentan solo la cara decorada con estaño, mientras que la cara sin decorar está cubierta con un vidriado de plomo transparente de color melado o verdoso.

Hemos comparado los "verde y manganeso" cordobeses emirales con los califales procedentes de ambientes domésticos (Fig. 15). Ambas producciones siguen la misma receta para la elaboración del vidriado opaco blanco, para el que se mezcla óxido de estaño, óxido de plomo y cenizas sódicas, siguiendo la receta abasí. En un primer momento utilizan una receta más cara, con mayor contenido de estaño y más cenizas sódicas. Sin embargo, con el paso del tiempo, en la etapa califal, cuando la producción se multiplica, parece que abaratan costes de producción, incorporando más plomo, que es más barato, y bajando los contenidos de estaño y de cenizas sódicas, que eran materiales más caros de conseguir, especialmente el primero que había que importarlo de otras zonas peninsulares.

Finalmente, se detecta un cambio de diseños decorativos (geométricos más complejos) y formas (p. ej. ataifores hemisféricos) con respecto a la vajilla vidriada de plomo transparente. Esto indicaría que el inicio de la tecnología del estaño en al-Andalus trajo consigo nuevos tipos y decoraciones, que no se habían documentado hasta el momento. 

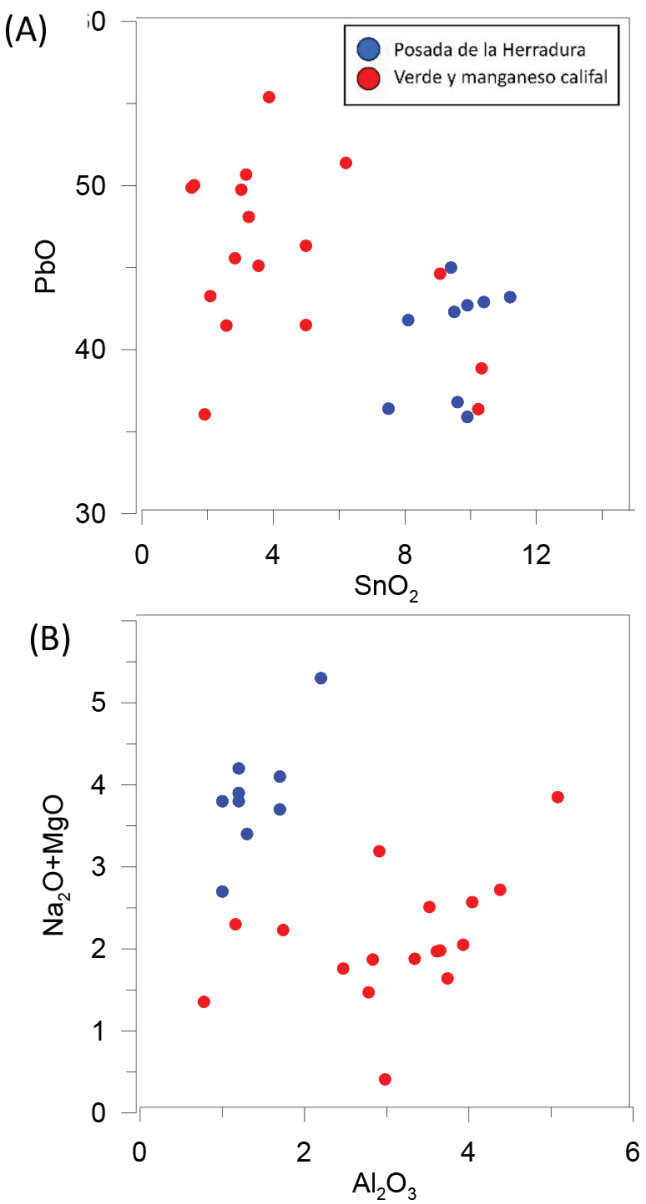

Fig. 15. Diagramas gráficos de la composición química de los vidriados opacos policromos, comparando Posada de la Herradura (PH) (en azul) y los verde y manganeso califales de varios yacimientos de Córdoba separados por colores: el blanco (en rojo), el verde (en verde) y el marrón (en marrón). A) $\mathrm{PbO}$ versus $\mathrm{SnO}_{2}$ y B) $\mathrm{Na}_{2} \mathrm{O}+\mathrm{MgO}$ versus $\mathrm{Al}_{2} \mathrm{O}_{3}$.

Si bien es cierto que dos rasgos comunes en ambas producciones son la ausencia de pie y la aplicación de los diseños decorativos sobre la cobertura vidriada de la pieza.

Por tanto, en relación al origen y/o influencias de las tradiciones tecnológicas de los vidriados de plomo transparente y de los vidriados opacos de estaño, la conexión tunecina queda absolutamente descartada, puesto que en Ifrīqiya utilizaron una técnica de vidriado transparente diferente y no controlaban la tecnología del estaño en el momento en el que se introdujo en al-Andalus. Por otro lado, se encuentran más similitudes entre las producciones cordobesas y las abasíes, como el uso de una receta de estaño común, diseños decorativos parecidos, uso de vidriados de plomo, etc., pero también desemejanzas, como las decoraciones sobrecubierta, la ausencia de vidriados alcalinos transparentes, variaciones en las formas de la vajilla de mesa, ausencia de pie, etc., que dificultan establecer un nexo claro entre ambas tradiciones.

\section{CONCLUSIONES}

El conjunto cordobés ilustra bien los inicios de la producción vidriada polícroma transparente y opacificada con estaño en el mundo Islámico occidental, donde los alfareros introdujeron nuevas formas, recetas de vidriado y diseños decorativos que, en cierta medida, no continuaron los criterios "oficiales" que serán característicos del periodo califal pleno. El periodo tardoemiral supuso un periodo breve pero muy creativo en cuanto a la tecnología del vidriado se refiere, en el que uno o varios talleres estuvieron funcionando en Córdoba, en un momento de transición política complicado protagonizado por las revueltas de Oman ben Hafsun y otros, o la independencia política de Pechina. Este corto periodo precede a otro que se caracterizó por la producción estandarizada de la producción vidriada de estaño y polícroma, conocida como "verde y manganeso", controlada por el poder Omeya, del periodo Califal (929-1009 d.C.), y que se traduce en una menor variedad de formas, tipos, colores y diseños decorativos que se repiten en los talleres andalusies, con ligeras variantes, y que son consecuencia de una producción a gran escala destinada a un mercado más amplio. El conjunto vidriado de la Posada de la Herradura representa una etapa anterior, en la que el consumo de vajilla vidriada estaba restringido a un sector más reducido y privilegiado de la sociedad cordobesa. De ahí que presenten decoraciones mucho más elaboradas que requieren más tiempo de ejecución, y recetas de vidriado que necesitan de un proceso de producción más complejo y, por extensión, más costoso. Ese es el motivo por el que algunas de las decoraciones y formas tardoemirales 
desaparecen, mientras que otras simplemente evolucionaron en el tiempo, al compás de nuevas modas y tendencias. Respecto a las producciones polícromas -tanto transparentes como opacas- llama la atención la simpleza de los diseños pintados, si lo comparamos con otras regiones contemporáneas o incluso con el periodo califal. Esto concuerda con la simplicidad de los diseños en las cerámicas pintadas y podría indicar que son los mismos alfareros cordobeses los que modelan, decoran y fabrican la receta del vidriado y que no existe aún una especialización como ocurría en los talleres orientales, en los que determinados artesanos se dedicaban exclusivamente a pintar y decorar las piezas y no participaban en todo el proceso productivo de la chaîne opèratoire.

Volviendo a la tesis de la producción local, cuando publicamos el artículo sobre la transición de los vidriados transparentes de plomo a los opacos de estaño, solo se tenía constancia arqueológica de algunos defectos de cocción en la zona alfarera del Zumbacón, Córdoba. Sin embargo, las pastas cerámicas y los vidriados no habían sido analizados y, por tanto, no podíamos comprobar si el conjunto estudiado era de producción local. Ahora podemos aportar más información. Las pastas cerámicas son todas finas de tipo calcáreo, mientras que los vidriados son diferentes para cada producción: transparente de plomo monocromo/ bícromo, transparente de plomo polícromo y opacificado con estaño. Los análisis apuntan a un origen local. De hecho, se han encontrado defectos de cocción de cerámicas vidriadas monocromas y bícromas en la zona alfarera de la ciudad (actual barrio del Zumbacón). En la misma excavación se han encontrado dos piezas vidriadas polícromas que, aunque no presentan defectos de cocción evidentes, repiten rasgos formales y decoraciones constatadas en otros yacimientos cordobeses. Sin embargo, no se han encontrado, por el momento, evidencias de producción local de cerámica vidriada con estaño de época emiral. Es cierto que no se ha excavado la zona alfarera cordobesa en su totalidad, solo un sector, y que es bastante probable que existieran varios talleres especializados en la producción vidriada, al igual que existió un número considerable de talleres orientados a la fabricación de cerámica sin vidriar (como lo demuestra el hallazgo de más de cien hornos datados en época emiral-primo califal). Por otro lado, recientes hallazgos han demostrado la producción cordobesa califal de cerámica verde y manganeso en Córdoba (SALINAS y PRADELL, 2020), lo que está en consonancia con que la tecnología del estaño comenzara en la capital de al-Andalus a finales del emirato y continuara durante la proclamación del Califato. No sabemos si existieron otros centros tempranos especializados en la tecnología del estaño, aunque por el momento lo consideramos poco probable. Así, las cerámicas con estaño encontradas en la Vega de Granada datadas como emirales no presentan evidencias suficientes como para probar la existencia de otro centro productor temprano (MOLERA et alii, 2017).

La tecnología del vidriado en al-Andalus no parece que empiece hasta mediados del siglo IX, muy tarde en comparación con otras regiones Islámicas, donde comenzaron a producirse cerámicas vidriadas en el siglo VIII (TITE et alii, 2015; WATSON, 2014). Como resultado de este comienzo más tardío, la fase de transición de los vidriados de plomo transparentes polícromos a los vidriados opacos de estaño fue muy corta (unos 20-30 años) en comparación con otros territorios donde este proceso llevó aproximadamente un siglo, como en el Mediterráneo central - Ifríqiya (Túnez) y Sicilia. De hecho, gracias a la información extraída del conjunto cordobés y de su comparación con otros repertorios cordobeses contemporáneos (tardoemirales) y posteriores (califales), se demuestra que una vez que se introdujo la tecnología del estaño, y después de un breve periodo de coexistencia, los vidriados de plomo transparentes polícromos desaparecen, al menos en Córdoba. Es cierto que a finales del periodo califal se documenta, en Córdoba, una producción de verde y manganeso sobre fondo melado, en vez del blanco opaco de estaño. Sin embargo, esta producción difiere de la anterior, puesto que el fondo es un vidriado de plomo enriquecido con óxido de hierro. Por el contrario, los 
polícromos emirales tienen un fondo transparente, sin colorantes añadidos.

Los vidriados transparentes polícromos muestran una composición y métodos de producción ligeramente diferentes con respecto a los vidriados monocromos y bícromos, sin que por el momento podamos precisar más. Respecto a la vajilla polícroma, tanto la transparente como la opaca comparten la ausencia de pie y la decoración sobrecubierta, aunque nuevas formas y diseños fueron introducidos con los vidriados opacos de estaño. Estos rasgos no parecen corresponderse con lo que estaba pasando en otras regiones de la cuenca mediterránea y tampoco en los territorios abasíes.

Nuestro estudio demuestra cómo aunque la tecnología del vidriado comenzó en alAndalus más tarde que en muchos territorios de la Dar al-Islam, sobre todo los orientales, una vez que la producción comenzó, creció y evolucionó rápidamente: primero como producto de lujo a pequeña escala y dirigido a un mercado privilegiado (como el que habitó en la casa de la Posada de la Herradura, en el barrio del Sabular), después el consumo de vajilla vidriada se extendió muy rápido, alcanzando a toda la población (como podemos ver en los arrabales occidentales cordobeses). Si bien es cierto que determinadas técnicas orientales no fueron asimiladas en al-Andalus durante el periodo omeya: como el uso del azul de cobalto y la loza dorada que, en este momento de finales del siglo IX-principios del X, quedaron restringidas al mundo abasí.

Aún queda por investigar las posibles rutas de introducción de la tecnología del vidriado de plomo y de estaño en al-Andalus, pero sí podemos descartar a Túnez como posible conexión, como se ha pensado durante algún tiempo, y explorar una ruta abasí para los vidriados blancos opacos de estaño.

\section{BIBLIOGRAFÍA}

AMORÓS, V. y GUTIÉRREZ, S. (en prensa): "De vidrios y vidriados: una primera revisión de la cerámica vidriada del Tolmo de Minateda (Hellín, Albacete)". En J. Coll \& E. Salinas (eds.) Tecnología de los vidriados en el oeste mediterráneo: Tradiciones islámicas y cristianas, pp. 33-49. Valencia.

ARDIZZONE F., PEZZINI, E. y SACCO, V. (2017): "Aghlabid Palermo: a new reading of written sources and archaeological evidence". The Aghlabids and their Neighbors: Art and Material Culture in Ninth-century North Africa, G.D. Anderson, C. Fenwick, M. Rosser-Owen (eds.), pp. 362-381. Leiden. https://doi.org/10.1163/9789004356047_019

ARMSTRONG, P., HATCHER, H. y TITE, M. (1997): "Changes in Byzantine glazing technology from the ninth to thirteenth centuries". En La céramique médiévale en Méditerranée. Actes du Ge Congrès, pp. 225-229. Aix-en-Provence.

BEN AMARA, A., SCHVOERER, M., DAOULATLI, A. y RAMMAH, M. (2001): "Jaune de Raqqada" et autres couleurs de céramiques glaçurées aghlabides de Tunisie (IX - X siècles)". Revue d'Archéométrie, 25, pp. 179-186. https://doi.org/10.3406/arsci.2001.1013

BEN AMARA, A., SCHVOERER, M., THIERRIN-MICHAEL, G. y RAMMAH, M. (2005): "Distinction de céramiques glaçurées aghlabides ou fatimides (IXe-Xlesiècles, Ifriqiya) parla miseen évidence de différences de texture au niveau de l'interface glaçure - terre cuite". ArchéoSciences, 29, pp. 35-42. https://doi.org/10.4000/archeosciences.458

CÁNOVAS, A. (2006): Informe de la AAP en la calle María Auxiliadora 17 y calle Jesús del Calvario (Córdoba). Córdoba.

CÁNOVAS, A. y SALINAS, E. (2010): "Actividad Arqueológica Preventiva en la calle María Auxiliadora 17 y calle Jesús del Calvario (Córdoba)". Anuario Arqueológico de Andalucía 2005, pp. 503-515.

CASTILLO, F.y MARTínEZ, R. (1993): "Producciones cerámicas en Bayyana”. I Encuentro de Arqueología y Patrimonio. La cerámica altomedieval en el sur de al-Andalus. Salobreña, 1990, pp. 67-116. Granada.

CRESSIER, P. y RAMMAH, M. (2007): "Sabra al-Mansûriya (Kairouan, Tunisie): résultats préliminaires des datations par radio carbone". Mélanges de l'École française de Rome. Moyen-Age, tome 119, n², pp. 468-477.

DAOULATLI, A. (ed.) (1994): Couleurs de Tunisie: 25 siecles de céramique. París.

DJELLID, A. (2011): "La céramique islamique du haut Moyen Âge en Algérie (IXe-Xe siècles): les problèmes de son étude", P. Cressier, E. Fentress (eds.). La céramique maghrébine du Haut Moyen âge (VIIle-Xe siècle). État des researches, problèmes et perspectives. École Française de Rome, pp. 147-158.

FRANÇOIS, V. (2005): "La vaisselle de table à Byzance: un artisanat et un marché peu perméables aux influences extérieures”, M. Balard, E. Malamut, J.-M. Spieser (eds.). Byzance et le monde extérieur. Contacts, relations, échanges, pp. 211-223. París. https://doi. org/10.4000/books.psorbonne.1868

FRANÇOIS, V y SHADDOUD, I. (2013): "Nouvel atelier de potier d'époque abbasside au sud de Tell Abou Ali à Raqqa". al-Rāfidān, vol. XXXIV, pp. 21-79.

GAYRAUD, R.-P. y VALLAURI, L. (2017): Fustat II. Fouilles d'Isțabl 'Antar. Céramiques d'ensembles des IXe et $X$ siècles. Institut français d'archéologie orientale. Fouilles de l'Ifao 75/Institut d'Archéologie Orientale. Le Caire.

GRAGUEB, S. (2017): "La céramique aghlabide de Raqqada et les productions de l'Orient islamique: parenté et filiation", G.D. Anderson, C. Fenwick, M. Rosser-Owen (eds.). The Aghlabids and their 
Neighbors: Art and Material Culture in Ninth-century North Africa, pp. 341-361. Leiden.

INNIGUEZ, C. y MAYORGA, J.F. (1993): "Un alfar emiral en Málaga". I Encuentro de Arqueología y Patrimonio. La cerámica altomedieval en el sur de al-Andalus. Salobreña, 1990, pp. 117-138. Granada.

LARREA, I. (2008): Memoria preliminar de la A.A.Pre en el E.D. SCz-Zumbacón (Córdoba). Córdoba.

MATIN, M., TITE, M. y WATSON, O. (2018): "On the origins of tin-opacified ceramic glazes: New evidence from early Islamic Egypt, the Levant, Mesopotamia, Iran, and Central Asia". Journal of Archaeological Science 97, pp. 42-66. https://doi.org/10.1016/j.jas.2018.06.011

MCPHILLIPS, S. (2012): "Continuity and innovation in Syrian artisanal traditions of the $9^{\text {th }}$ to $13^{\text {th }}$ centuries". Bulletin d'études orientales, tome LXI, pp. 447-473. https://doi.org/10.4000/beo.1025

MOLERA, J., PRADELL, T., SALVADÓ, N. y VENDRELL-SAZ, M. (2009): "Lead Frits in Islamic and Hispano-moresque Glazed Productions". From Mine to Microscope. Advances in the Study of Ancient Technology, pp. 11-22. Oxford: Oxbow.

MOLERA, J., CARVAJAL, J.C., MOLINA, G. y PRADELL, T. (2017): "Glazes, colourants and decorations in early Islamic glazed ceramics from the Vega of Granada (9th to 12th centuries AD)". Journal of Archaeological Science: Reports. https://doi.org/10.1016/j. jasrep.2017.05.017

MORENO, M., VARGAS, S. y GARCÍA, B. (2006): Informe Memoria de la Supervisión Arqueológica en la Antigua Posada de la Herradura. Córdoba.

MORILLO, A. (2017): "La cerámica vidriada romana y su presencia en Hispania". En C. FERNÁNDEZ, A. MORILO Y M. ZARZALEJOS (eds.). Manual de cerámica romana III. Cerámicas romanas de época altoimperial en Hispania. Cerámica común de mesa, cocina y almacenaje. Imitaciones hispanas de producciones romanas universales, pp. 381-433. Alcalá de Henares.

NORTHEDGE, A. y KENNET, D. (1994): "The Samarra Horizon". En E. Grube (ed.) Cobalt and Lustre, The Nasser D. Khalili Collection of Islamic Art, V IX, pp. 21-35. Oxford: Khalili Research Centre, University of Oxford.

NORTHEDGE, A. (1997): "Les origines de la céramique à glaçure polychrome dans le monde islamique", en G. Demians D'Archimbaud (ed.), VI C.I.C.M.M.O. pp. 213-224. Aix-en-Provence.

PEÑA, Y., GARCÍA-ENTERO, V.y ZARCO, E. (en prensa): "Crisoles para la elaboración de vidrio de época visigoda localizados en la Vega Baja de Toledo. Nuevas consideraciones para el debate sobre las llamadas cerámicas vidriadas espesas o cerámicas vidriadas pre-emirales". En J. Coll \& E. Salinas (eds.), Tecnología de los vidriados en el oeste mediterráneo: Tradiciones islámicas y cristianas, pp. 19-31. Valencia.

ROSSELLÓ, G. (1978): Ensayo de sistematización de la cerámica árabe en Mallorca. Palma de Mallorca.

ROSSELLÓ, G. (1991): El nombre de las cosas en al-Andalus, una propuesta de terminología cerámica. Palma de Mallorca.

SALINAS, E. (2013): "Cerámica vidriada de época emiral en Córdoba". Arqueología y Territorio Medieval, 20, pp. 67-96. https://doi. org/10.17561/aytm.v20i0.1446

SALINAS, E. y PRADELL, T. (2018): "The transition from lead transparent to tin-opacified productions in the western Islamic lands:
al-Andalus, C. 875-929 CE". Journal of Archaeological separar Science, 94, pp. 1-11. https://doi.org/10.1016/j.jas.2018.03.010

SALINAS, E. y PRADELL, T. (en prensa): "The first glaze production centres in al-Andalus (late $9^{\text {th }}$-early $10^{\text {th }}$ centuries): Pechina, Córdoba and Málaga", Tecnología de los vidriados en el oeste mediterráneo: Tradiciones islámicas y cristianas. Valencia

SALINAS, E. y PRADELL, T. (2020): "Madīnat al-Zahrā' or Madīnat Qurtuba? First evidences of the Caliphate tin glaze production of 'verde y manganeso' ware". Archaeological and Anthropological Sciences, 12, Article number: 207. https://doi. org/10.1007/s12520-020-01170-7

SALINAS, E., MOLERA, J. y PRADELL, T. (2019a): "Glaze production at an early Islamic workshop in al-Andalus". Archaeological and Anthropological Sciences, 11, pp. 2201-2213. https://doi. org/10.1007/s12520-018-0666-y

SALINAS, E., PRADELL, T., MATIN, M. y TITE, M. (2019b): "From tin- to antimony-based yellow opacifiers in the early Islamic Egyptian glazes: Regional influences and ruling dynasties". Journal of Archaeological Science: Reports, 26, 101923. https://doi. org/10.1016/j.jasrep.2019.101923

TAXEL, I. (2014): "Luxury and common wares: socio-economic aspects of the distribution of glazed pottery in Early Islamic Palestine". Levant, 46.1, pp. 118-139. https://doi.org/10.1179/0075891413Z.00000000036

TESTOLINI, V. (2018): Ceramic Technology and Cultural Change in Sicily from the 6th to the 11th century AD. PhD thesis, University of Sheffield. http://etheses.whiterose.ac.uk/24131/ https://doi. org/10.15131/shef.data.11567910

TITE, M., WATSON, O., PRADELL, T., MATIN, M., MOLINA, G., DOMONEY, K. y BOUQUILLON, A. (2015): "Revisiting the beginnings of tin-opacified Islamic glazes". Journal of Archaeological Sciences, 57, pp. 80-91. https://doi.org/10.1016/j.jas.2015.02.005

WAKSMAN, S.Y., CAPELLI, C., PRADELL, T. y MOLERA, J. (2014): "The ways of the lustre: Looking for the Tunisian connection". Craft and science: International perspectives on archaeological ceramics, pp. 109-116. https://doi.org/10.5339/uclq.2014.cas.ch12

WALTON, M.S. (2004): A materials chemistry investigation of Archaeological lead glazes, PhD thesis, Oxford University.

WATSON, O. (1999): "Report on the glazed ceramics", P. Miglus (ed.), Ar-Raqqa I. Die Frühislamische Keramik von Tall Aswad.; pp. 81-87, taf. 94-99. Mainz.

WATSON, O. (2014): "Revisiting Samarra: the rise of the Islamic glazed pottery”. Beiträge Zur Islamischen Kunst Und Archäologie, 4, pp. 125-144.

WHITCOMB, D. (1989): "Coptic glazed ceramics from the excavations at Aqaba, Jordan". Journal of American Research Centre in Egypt, 26, pp. 167-182. https://doi.org/10.2307/40000705

WOOD, N., DOHERTY, C. y OWEN, M. R. (2009): "A Technological Study of Iraqi Copies of Chinese Changsha and Chinese Sancai Wares found at Samarra". Gu Taoci Kexue Jishu 8: ISAC'09.; pp. 154180. Beijing 